Pontifícia
$U_{\text {niversidade }}$ Católica $_{\text {Do Rio de Janeiro }}$

Francisco André Pereira Mendes

\title{
Análise dos Efeitos de Cargas de Serviço em Juntas Aparafusadas
}

Projeto de Graduação

Projeto de Graduação apresentado ao Departamento de Engenharia Mecânica da PUC-Rio.

Orientador: Jaime Tupiassú Pinho de Castro, PhD. 


\section{Agradecimentos}

Agradeço à todo o corpo docente e secretárias do Departamento de Engenharia Mecânica da PUC-Rio por todo o apoio durante esses anos, em especial ao meu professor orientador Jaime Tupiassú, quem me ensinou valores e conhecimentos incalculáveis, e sempre prestou auxílio durante o projeto.

Agradeço à PUC-Rio, nas pessoas de Augusto Sampaio e David Azulay, que me permitiram estar escrevendo esse texto.

Agradeço à minha família de sangue que sempre me apoiou em todos os momentos e nunca deixou de acreditar em mim, me dando sempre a base e a confiança necessárias. Obrigado por estarmos sempre juntos.

Agradeço à minha namorada Maria Júlia Martins, grande incentivadora, amiga, e companheira de vitórias e derrotas ao longo dos últimos três anos. Obrigado pelos carinhos, mensagens, passeios e todo o suporte.

Agradeço à minha família sem laços de sangue constituída por Erick Posse, Gabriela Wegmann, Murilo Oliveira e Gabriela Sertã, que sempre levantam o astral e nunca me abandonaram nem nos piores momentos.

Agradeço aos meus amigos Teodoro, Henrique, Sagrilo, Bastos, Cunha, Amoedo, Gutão, Fred, e Ingrid, que estiveram comigo desde os tempos do saudoso Colégio de São Bento, além de Tavinho, Adriel, Heitor, Formosinho, Gisele e Júlia, colegas que a PUC me deu ao longo de todo esse tempo.

Agradeço aos meus amigos e colegas da turma 33R do primeiro período na PUC, principalmente Pedro Gomes, Matheus Hoffmann e Victória Oliveira, exímios companheiros de histórias e piadas sem graça.

Agradeço aos também professores Mário Germino, Arthur Braga e Mauro Speranza pela confiança, credibilidade e auxílio em meu trabalho desde o primeiro período na PUC.

Agradeço à todo o Laboratório de Sensores à Fibra Óptica pelo aprendizado, experiência, histórias, carinho e confiança ao longo de quase dois anos.

Agradeço à toda equipe da $C$-Tank por me fornecer o suporte necessário para o aprendizado, além de motivação, companheirismo e paciência comigo.

Agradeço aos técnicos Euclides (LEM), Marques (LEM) e Carlos (Geotecnia), e ao Julian (Fadiga) por me ajudarem a realizar serviços considerados simples, mas que não poderiam deixar de ser executados.

Agradeço, por fim, à todos os envolvidos em meu crescimento pessoal e profissional não antes citados ao longo de quase 23 anos. 


\section{Resumo}

\section{Análise dos Efeitos de Cargas de Serviço em Juntas Apa- rafusadas}

Analisar efeitos de cargas de serviço é de suma importância para calcular vida à fadiga de tais componentes. Os experimentos foram realizados com intuito de comprovar as hipóteses utilizadas para diferentes projetos, incluindo constantes e fatores de aproximação pouco explicados na literatura. Atualmente, o projeto à fadiga de juntas aparafusadas leva em consideração a distribuição das carga em formato de um tronco de cone com angulação $\alpha$ de $30^{\circ}$. O objetivo deste trabalho é desmembrar essa modelagem e verificar outras hipóteses que podem ser aplicadas, considerando também efeitos de pré-carga no parafuso por meio de experimentos controlados. Obtevese como resultado que outros métodos acabam sendo muito conservadores e que o tronco de cone deve ser melhor explorado para aprimorar as previsões.

\section{Palavras-chave}

Parafusos; cargas de serviço; fadiga de parafusos; juntas aparafusadas; pré-carga; carregamentos axiais; rigidez de parafusos. 


\section{Abstract}

\section{Analysis of the Effects of Service Loads on Bolted Joints}

Analyzing the effects of service loads is very important to calculate fatigue life of these components. The experiments were carried out with the purpose of proving the hypotheses used for different projects, including constants and approach factors not very well explained in the literature. Currently the fatigue design of bolted joints tankes into account the distribution of the load in the shape of a cone trunk with $\alpha 30^{\circ}$. The major objective of this study is to dismember this modeling and verify other hypotheses that can be used, also considering preload effects on the screw by means of controlled experiments. It has been found that other methods were very conservative and that the cone trunk should be better exploited to raised our previsions.

\section{Keywords}

Bolts; service loads; fatigue; bolted joints; pre-loading; axial loads; joint stiffness. 


\section{Sumário}

1 Introdução $\quad 8$

2 Classificação de Elementos de uma Junta Aparafusada $\quad 10$

$\begin{array}{lll}2.1 \text { Parafusos } & 10\end{array}$

2.2 Membros das Juntas Aparafusadas 14

$\begin{array}{lll}2.3 & \text { Arruelas } & 15\end{array}$

$\begin{array}{lll}2.4 & \text { Porcas e Contra Porcas } & 16\end{array}$

3 Revisão Bibliográfica $\quad 18$

3.1 Determinação da Pré-Carga de Parafusos $\quad 19$

3.2 Determinação da Rigidez de Juntas Aparafusadas 21

3.3 Atuação de Forças Axiais 24

3.4 Fator de Carga 24

$\begin{array}{ll}3.5 & \text { Fadiga de Parafusos } \\ 3.6 & 25\end{array}$

3.6 Gráfico de decomposição de carga externa 26

4 Corpo de Prova $\quad 28$

$\begin{array}{lll}4.1 & \text { Rigidezes } & 30\end{array}$

5 Métodos Revisados 32

5.1 Teste de Torque 32

5.2 Teste de Tração 33

5.3 Teste de Fadiga 33

6 Dados Experimentais $\quad 35$

6.1 Equipamentos e Materiais $\quad 35$

$\begin{array}{ll}6.2 \text { Preparação do Experimento } & 35\end{array}$

6.3 Métodos Empregados 38

6.4 Aquisição de Dados 39

7 Resultados e Discussões $\quad 40$

7.1 Teste de Torque 40

7.2 Teste de Tração 42

7.3 Teste de Fadiga 44

8 Conclusões $\quad 47$

$9 \quad$ Sugestões para trabalhos futuros $\quad 48$ 


\section{Lista de figuras}

2.1 Elementos de uma Junta Aparafusada $\quad 10$

2.2 Ilustração das definições das características de um parafuso 11

2.3 Resumo das características que um parafuso pode possuir - Fonte [1] 12

2.4 Ilustração das terminologias de medição de parafusos [2] 13

2.5 Exemplo da definição de Classe de Resistência de um parafuso 13

2.6 Localização das resistências especificadas no gráfico tensãodeformação real 14

2.7 Tipos de juntas 14

$\begin{array}{ll}2.8 \text { Tipos de arruelas } & 15\end{array}$

2.9 Tipos de porcas 16

2.10 Tipos de porcas rápidas 16

$\begin{array}{ll}2.11 \text { Tipos de porcas de travamento } & 17\end{array}$

3.1 Cargas aplicadas a uma junta aparafusada 18

3.2 Tipos de pré-carga [3] 19

3.3 Dimensões sugeridas para desenvolver a determinação das rigidezes [2] 22

3.4 Método do cone de pressão [4] 23

3.5 Definição de cargas para fadiga [5] 25

3.6 Efeitos existentes em um diagrama de junção 26

3.7 Variáveis empregadas para construção de um diagrama de junção 27

3.8 Rigidezes relativas 27

3.9 Relações entre as forças atuantes em uniões aparafusadas [6] 27

4.1 Parafuso M20 utilizado como corpo de prova 28

4.2 Cabeça do parafuso M20 utilizado 28

4.3 Elementos utilizados para elaboração do procedimento experimental 29

4.4 Junta aparafusada a ser analisada 30

6.1 Parafuso com rebaixo 36

6.2 Datasheet do Strain Gage utilizado - MM CEA-06-125UE 36

6.3 Disposição dos strain gages ao longo do corpo de prova e sua respectiva ponte de Wheatstone - [7] 37

6.4 Parafuso com os strain gages colados 37

6.5 Conexões finais dos strain gages 38

7.1 Teste para verificar relação Torque $T$ e Força de Pré-carga $F_{i} \quad 40$

7.2 Gráfico do resultado de Força vs Torque 42

7.3 Corpo de prova posicionado na máquina de tração 43

7.4 Gráfico do resultado do teste de tração 43

7.5 Gráfico do resultado do teste cíclico até $25 \mathrm{kN}$

7.6 Gráfico do resultado do teste cíclico 30 kN 46 


\section{Lista de tabelas}

2.1 Normas utilizadas para projeto de elementos de juntas 10

3.1 Variações do fator $\kappa_{R} \quad 20$

4.1 Características do Corpo de Prova utilizado 29

4.2 Dimensões dos elementos constituintes da junta 30

7.1 Resultados de Deformação em função do Torque aplicado 41

7.2 Resultados de Força em função do Torque aplicado 41

7.3 Resultados de Deformação em função do carregamento 44

7.4 Fatores utilizados no dimensionamento 44

7.5 Resultados de Deformação em função do carregamento de máximo 25kN 45

7.6 Resultados de Deformação em função do carregamento de máximo 30kN 46 


\section{1 \\ Introdução}

Com intuito de facilitar montagem e reparo, projetos de engenharia utilizam variações de acoplamentos de componentes. Para executar um acoplamento estável, seguro e sem riscos à saúde estrutural dos materiais e dos operadores, é necessário um estudo intensivo sobre fixadores e junções.

A grande aplicabilidade de parafusos em juntas é justificada pela necessidade de desmontar tais componentes. O uso de colas ou resinas, por mais que ofereçam maiores resistências e maior diversidade de aplicações, não costumam ser muito empregadas. Para se ter uma ordem de grandeza, um avião possui cerca de 2 milhões de parafusos. Com uma quantidade grande desses fixadores e o seu valor individual podendo chegar a centenas de dólares, fabricantes buscam novas soluções para reduzir tais custos. Porém, esses estudos acabam utilizando métodos clássicos e pouco explicados na literatura.

Comparando com outros tipos de juntas, a união por parafusos também apresenta algumas desvantagens. Uma delas é não garantir que o aperto inicial se mantenha, devido a deslocamentos e vibrações, havendo frequentemente a necessidade do uso de dispositivos de segurança contra o afrouxamento do parafuso.

Como parte de todo projeto de engenharia, é necessário estudar os tipos de falha mais comuns. Para o caso de parafusos, elementos muito importantes na união de membros, os tipos de falha são tração, cisalhamento, fadiga, corrosão e fluência.

Diversos autores já estudaram sobre essas falhas. Um estudo muito interessante e didático é apresentado por Grimsmo et al. [8]. Eles apresentam três tipos mais comuns de falha em parafusos: falha na estrutura do parafuso, falha na rosca do parafuso, e falha na rosca da porca. Foram feitos diversos testes e suposições para chegar ao resultado de que parafusos com maior comprimento de rosca tendem a ter fraturas no corpo do parafuso, enquanto os de menor comprimento de rosca tendem a ter fraturas nos filetes. Outro estudo interessante sobre tipos de fratura é um dos pesquisadores Wentzel et al. [9], que remete à fadiga de parafusos sob flexão.

Por fim, os estudos de J.G. Williams et al. [4] foram utilizados como ponto de partida deste trabalho. Nesse artigo são abordadas análises teóricas, computacionais e experimentais acerca de uma junta externamente carregada. Os resultados comprovam que há efeitos não lineares pouco capazes de serem 
previstos, mas que, acima de tudo, os valores encontrados possuem uma tendência próxima e dispersão não tão significativa.

O primeiro tópico para melhor compreendimento do assunto por parte do leitor é apresentado nos capítulos 2 e 3 . O capítulo 2 explica de maneira sucinta como são classificados os parafusos, as juntas aparafusadas e os membros fixadores que comungam para maior estabilidade e confiança da junta. As principais características de parafusos são explicadas nesse capítulo. O capítulo 3 , por sua vez, tem como objetivo explicar os principais efeitos sofridos pelos parafusos ao serem solicitados por diferentes tipos de carga. Os métodos explicados foram os adotados pelas referências mais conhecidas em termos de projetos mecânicos [2, 6, 10, 11], além da norma 898-1:2013 [12] sobre parafusos rosqueados.

O capítulo 5 apresenta a rotina dos testes a serem empregados, bem como suas principais equações. Neste capítulo, os conceitos adquiridos no capítulo 3 são aplicados para atender aos objetivos.

Com essa base teórica pré-estabelecida, pode-se então adentrar na parte experimental deste trabalho. O capítulo 4 destaca as características do parafuso utilizado como corpo de prova. As informações foram coletadas de tabelas e dos capítulos anteriores. Já o capítulo 6 traz todo o processo da aquisição dos dados experimentais. São bem detalhadas a seleção, preparação e montagem dos equipamentos, além de informações minuciosas sobre a instrumentação do parafuso, como a escolha do strain gage e a orientação da montagem para leitura.

Por fim, são apresentados no capítulo 7 os resultados obtidos numericamente e experimentalmente, além das comparações entre os dois métodos. Esses resultados são devidamente comentados e justificados no capítulo 8, junto às conclusões obtidas pelas comparações e aproximações utilizadas.

É de suma importância destacar que este projeto foi realizado com todo o cuidado e preocupação necessários para garantir sua validade. Porém, durante o estudo foram feitas algumas descobertas que podem aumentar a precisão e a exatidão dos resultados, mas não foram aplicadas por questões de tempo ou conhecimento prévio disponível. Tais detalhes são citados no capítulo 9. Nesse capítulo também são mencionadas sugestões de estudos futuros utilizando esse presente estudo como base. 


\section{2}

\section{Classificação de Elementos de uma Junta Aparafusada}

Antes de qualquer estudo mais profundo, é importante discriminar os elementos de uma junta aparafusada. A figura 2.1 mostra os principais elementos. São eles: parafuso, membros, porca, contraporca e arruela.

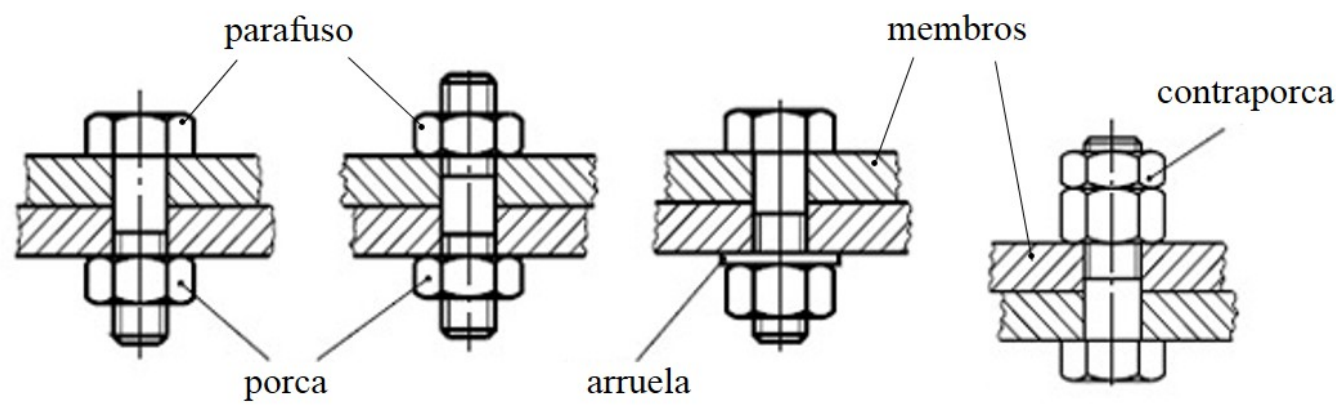

Figura 2.1: Elementos de uma Junta Aparafusada

Vale ressaltar que tanto as propriedades mecânicas quanto a geometria de cada componente são de fundamental importância para o comportamento mecânico da junta. Para tal, normas, tais como as ISO, são estabelecidas como forma de unificar o projeto. A tabela 2.1 apresenta as normas ISO referentes aos elementos que serão melhor explicados a seguir.

Tabela 2.1: Normas utilizadas para projeto de elementos de juntas

\begin{tabular}{|ccc|}
\hline Elemento & Propriedades Mecânicas & Geometria de Projeto \\
\hline Parafuso & ISO $898-1$ & ISO 4016 e ISO 724 \\
\hline Arruela & ISO 7089 & ISO 7089 \\
\hline Porca & ISO $898-2$ & ISO 4032 e ISO 724 \\
\hline
\end{tabular}

\section{1}

Parafusos

Os parafusos são usados tanto para manter elementos unidos, como no caso de parafusos de fixação, quanto para mover cargas, como no caso dos chamados parafusos de potência, ou parafusos de avanço. Parafusos utilizados para fixação podem ser arranjados para resistir a cargas de tração, de cisalhamento, ou ambas.

Para ser considerado parafuso, dois requisitos básicos são necessários. O primeiro é a rosca e o segundo é o dispositivo de atarraxar, que não muito 
raramente é confundido com o tipo de cabeça. Além desses requisitos, parafusos são classificados quanto às suas partes, isto é:

a) Cabeça: quadrada, sextavada, oval etc;

b) Pescoço: quadrado, cilíndrico, estriado etc;

c) Corpo: parcial ou totalmente rosqueado, diâmetro contínuo ou não;

d) Extremidade: cilíndrica, cônica etc;

e) Parte atarraxante: fenda, sextavado interno, furo transversal, cabeça ou pescoço sextavado etc;

f) Rosca: ISO, Unificada Americana (UN), quadrada, primeiro padrão inglês (Whitworth) etc.

A figura 2.2 ilustra as nominações citadas acima, enquanto a figura 2.3 apresenta uma tabela resumo com as principais variações dentro das classificações de parafusos.
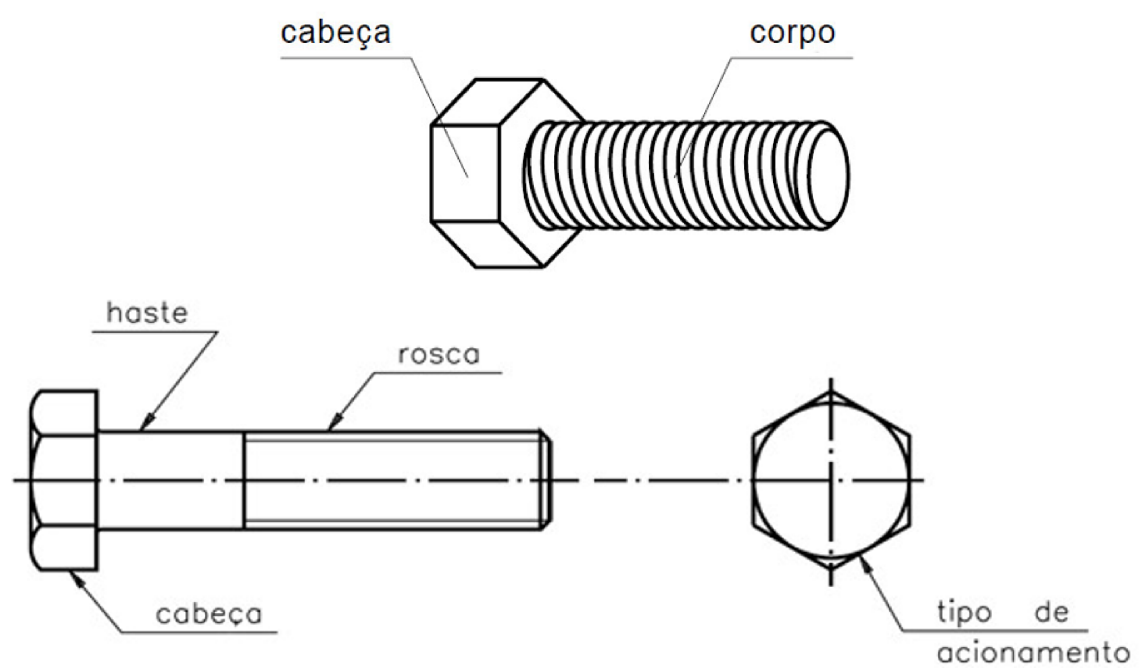

Figura 2.2: Ilustração das definições das características de um parafuso

Além das classificações, outro ponto importante dos parafusos são as nomeações dadas à cada componente. Em relação à parte rosqueada no corpo de um parafuso, é necessário fazer algumas nomeações, conforme ilustrado na figura 2.4, e explicados detalhadamente abaixo a partir das definições de Shigley[2].

O diâmetro maior é o maior diâmetro de uma rosca de parafuso, mas não é igual ao diâmetro nominal do parafuso $(d)$. O diâmetro menor $\left(d_{r}\right)$, 


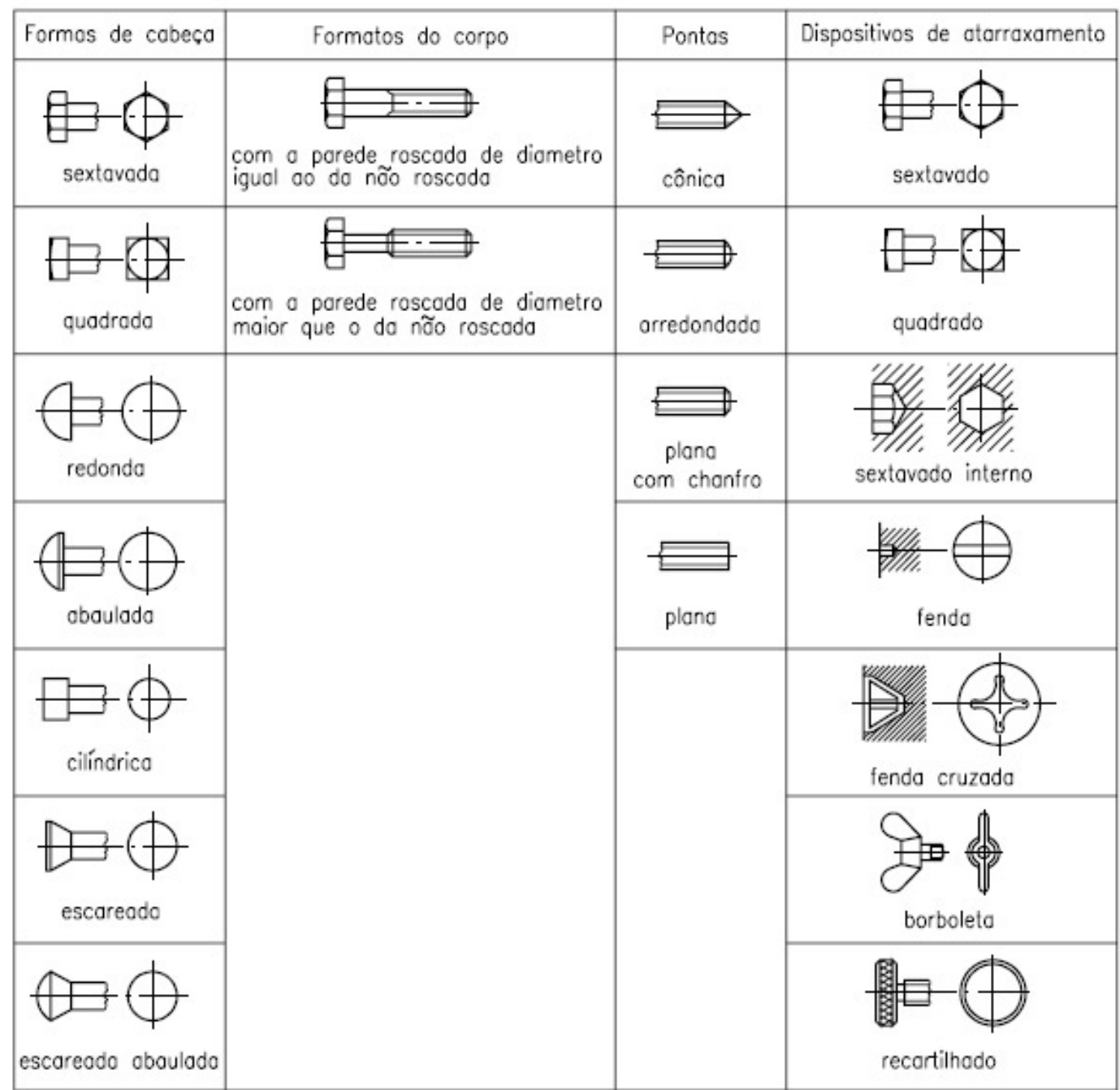

Figura 2.3: Resumo das características que um parafuso pode possuir - Fonte [1]

também conhecido como diâmetro de raiz, é o menor diâmetro de uma rosca de parafuso, dado pela equação (2-1). O diâmetro de passo $\left(d_{p}\right)$, por sua vez, é teórico e encontra-se entre os diâmetros maior e menor, conforme a equação $(2-2)$.

$$
\begin{aligned}
& d_{r}=d-1.226869 \cdot p \\
& d_{r}=d-0.649519 \cdot p
\end{aligned}
$$

O passo em unidades métricas é a distância entre duas formas adjacentes de rosca medidas paralelamente ao centro da rosca, isto é, a distância entre duas cristas ou entre duas raízes. Por outro lado, em unidades inglesas o passo é o número de formas de rosca por polegada.

Não representado diretamente na figura 2.4, o avanço é a distância que a porca se move paralelamente ao centro do parafuso quando a porca completa 
uma volta. No caso de um parafuso com rosca única semelhante ao ilustrado abaixo, o avanço é igual ao passo.

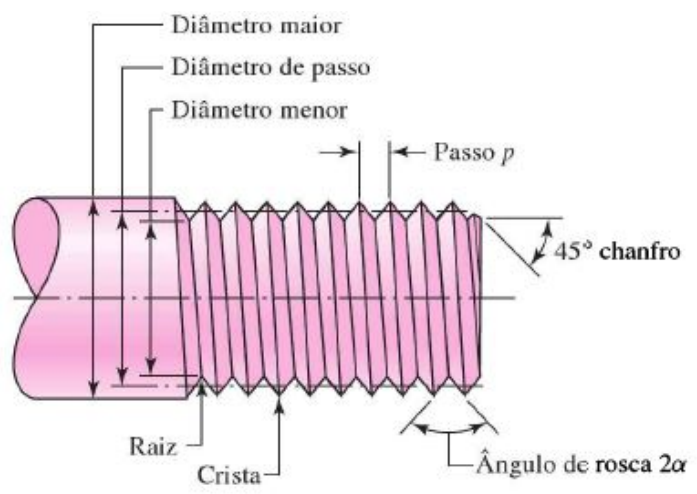

Figura 2.4: Ilustração das terminologias de medição de parafusos [2]

Apresentado na figura 2.4, é importante frisar que o ângulo $2 \alpha$ que aparece é referente ao ângulo de rosca, e não o ângulo do método do cone de pressão a ser estudado a seguir. O semi-ângulo de rosca para perfis métricos M é de $60^{\circ}$.

Outra característica fundamental para a classificação de um parafuso é a sua classe de resistência. Quanto maior for a classe de resistência do parafuso, menor será a sua ductilidade, porém maior será a sua capacidade de gerar força. A classe é representada por dois números sob o formato XX.Y. O primeiro número faz referência ao valor da Resistência à Tração Nominal $\left(S_{u t}\right)$ mínima. Para se obter tal valor em MPa, deve-se multiplicar XX por 100. O segundo índice faz referência ao Valor da Resistência ao Escoamento Nominal $\left(S_{y}\right)$. O índice é a porcentagem da Resistência à Tração Nominal mínima que corresponde à Resistência ao Escoamento. A figura 2.5 explicita o caso de um parafuso de classe 10.9.



Figura 2.5: Exemplo da definição de Classe de Resistência de um parafuso

Além dessas duas resistências, é especificado também para cada classe de resistência a sua Resistência à Carga de Prova $\left(S_{P}\right)$. Essas classes são representadas no gráfico tensão vs deformação real a seguir. 


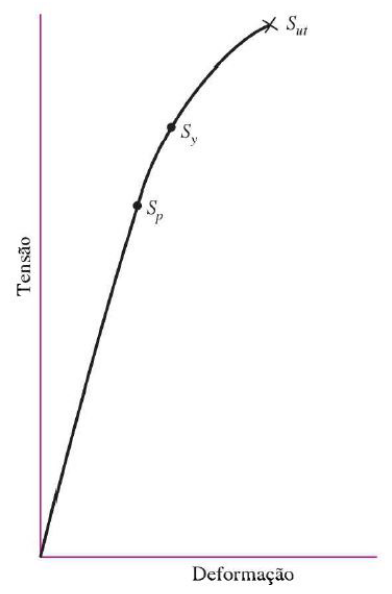

Figura 2.6: Localização das resistências especificadas no gráfico tensãodeformação real

O parafuso utilizado como referência para o presente estudo será retratado no capítulo 4 .

\section{2}

\section{Membros das Juntas Aparafusadas}

Juntas são definidas por um conjunto de duas ou mais placas unidas. No caso de juntas aparafusadas, a união é dada por parafusos. Como critério da junta, elas devem se manter rigidamente fixas e unidas, independente das cargas de trabalho nela aplicadas.

Os tipos de juntas mais comuns são as juntas de tração e as juntas de cisalhamento, descritas na figura 2.7.

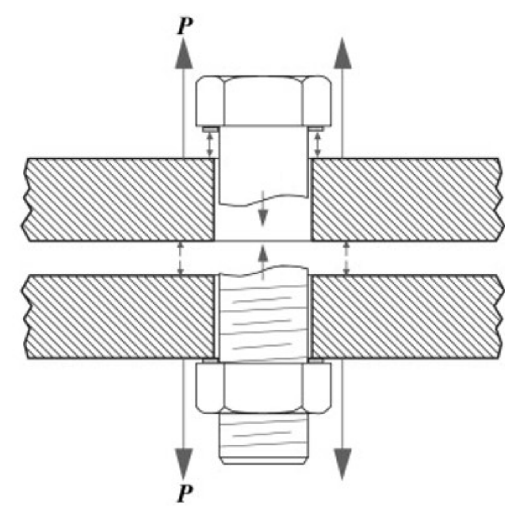

2.7(a): Junta de Tração

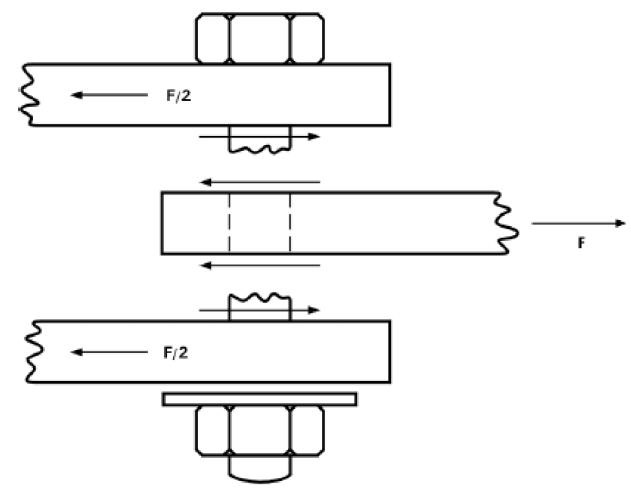

2.7(b): Junta de Cisalhamento

Figura 2.7: Tipos de juntas 


\section{3}

\section{Arruelas}

Arruela é um disco fino com um furo, que costuma ser centralizado. São utilizadas para distribuir a carga aplicada, além de ser projetada para suportar tal carga. Além disso, podem ser utilizadas como espaçadores, mola, ou dispositivos de bloqueio. O material constituinte geralmente é metal ou plástico.

Arruelas de aço endurecido são utilizadas quando a força de compressão da cabeça de parafuso sobre a parte sujeitada necessita ser distribuída sobre uma área maior que a área da cabeça do parafuso ou da porca. Arruelas nãometálicas são usadas quando é necessário isolamento elétrico do parafuso com relação à parte.

Arruelas de travamento são utilizadas para evitar o afrouxamento espontâneo de porcas padronizadas (em oposição a porcas de travamento), arruelas de travamento podem ser utilizadas sob a porca de um parafuso ou sob a cabeça de um parafuso de máquina. A arruela partida ou de pressão é de aço endurecido e atua com uma mola sob a porca.
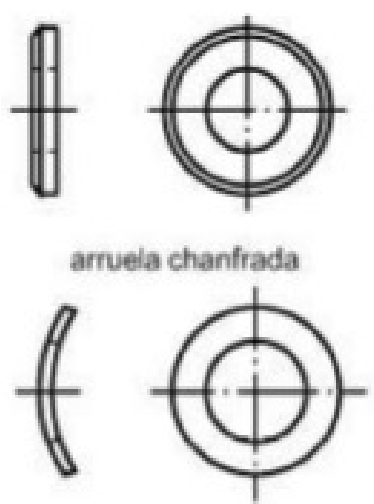

arruela curva de pressầo

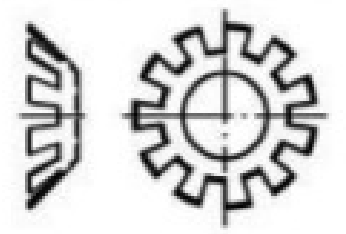

arruela com dentes cônicos
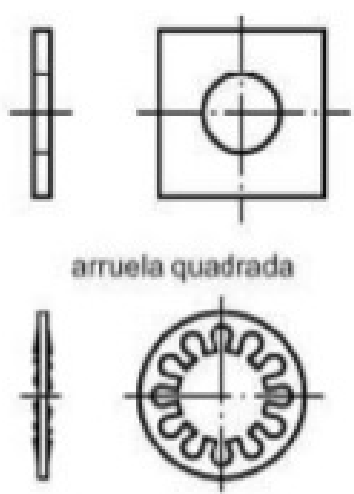

arruela com dentes internos

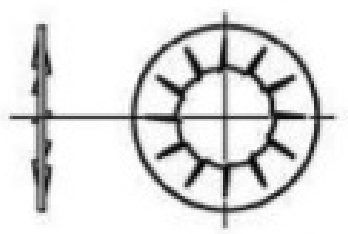

arruela com serrilhado interno

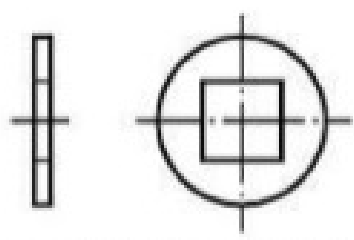

arruola do furo quadrado

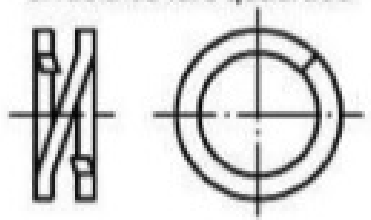

arruela dupla de pressẫo

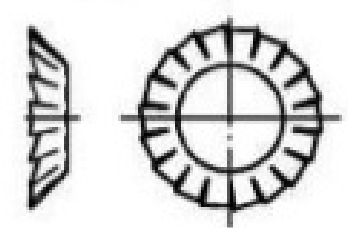

arruela com serrilhado cônico

Figura 2.8: Tipos de arruelas 


\section{4}

\section{Porcas e Contra Porcas}

Quando os membros da junta não possuem rosca interna, a solução para se fixar é adicionar um parafuso com uma porca. A porca, portanto, possui o propósito de segurar duas ou mais partes juntas através do atrito entre a rosca externa do parafuso e sua rosca interna. Ela é uma peça de forma prismática ou cilíndrica geralmente metálica.

A porca de aperto é uma versão estreita da porca hexagonal padrão e é utilizada em combinação com a porca padrão para travar esta ao parafuso. A porca de castelo tem sulcos para inserção de um pino através de um furo passante ao parafuso e que evita que a porca trabalhe frouxa. Uma porca cega é utilizada com propósitos decorativos e a porca de borboleta permite remoção sem necessidade de utilização de ferramentas.

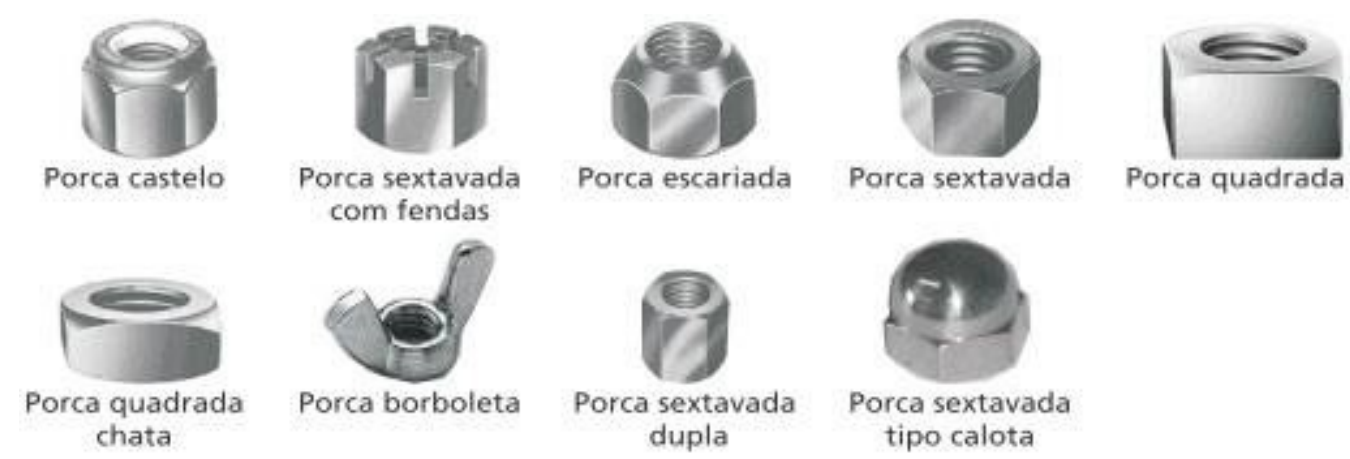

Figura 2.9: Tipos de porcas

Existem também as chamadas porcas rápidas. São denominadas assim por serem apenas uma acoplamento de fácil montagem. Por tal característica, são muito utilizadas em montagens de chapas em locais de difícil acesso.



Figura 2.10: Tipos de porcas rápidas 
Além das porcas convencionais, existem também as porcas de travamento, mais conhecidas como contraporcas. Duas porcas apertadas conjuntamente no parafuso ou uma porca de castelo com um pino, em ambos os casos, conseguem evitar o afrouxamento espontâneo devido a vibração.

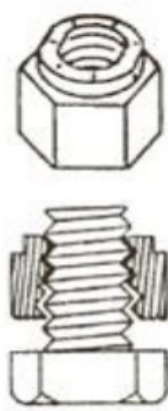

Porca de travamento eliptica
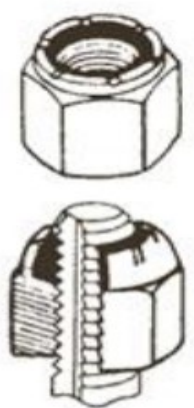

Porca de travamento com inserto de náilon



Porca de travamento por pino



Porca de travamento com flange

Figura 2.11: Tipos de porcas de travamento 


\section{3}

\section{Revisão Bibliográfica}

Conforme explicitado na seção 2.2, juntas podem sofrer diversos tipos de carregamento. A figura 3.1 apresenta as principais cargas em ação de uma junta (axial, aperto e cisalhamento).

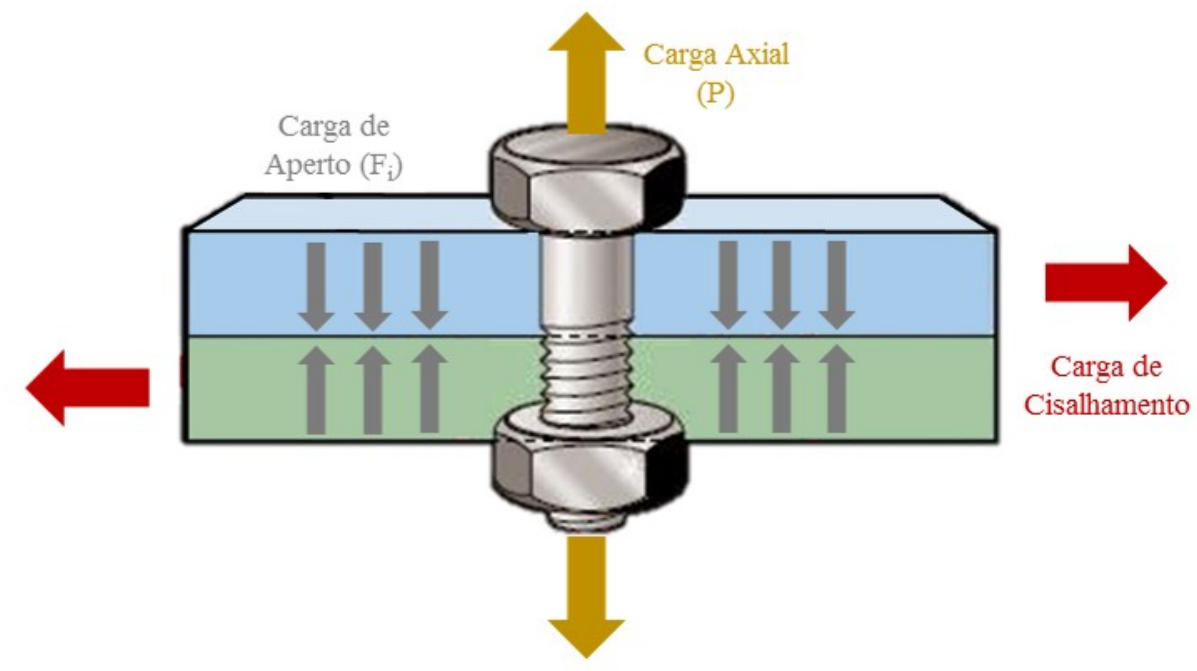

Figura 3.1: Cargas aplicadas a uma junta aparafusada

A geometria peculiar de uma união por parafusos colabora para a complexidade do estado de tensões atuante nela. É importante recordar que cada filete sofre uma carga diferente atuante [8]. Apesar de a montagem de uma junta ser simples e de amplo uso, sua modelagem é complexa.

A teoria convencional utilizada por grandes referências $[2,6,10,11]$ para modelar tal situação assume que a configuração dos parafusos e os membros dessa junta podem ser representada como molas lineares. Essa modelagem simplifica a análise, mas não a torna trivial.

Ao carregar uma junta aparafusada, as cargas são distribuídas, mas não de maneira uniforme. Portanto, para um dimensionamento cauteloso, é importante caracterizar as cargas atuantes e suas parcelas.

Além disso, é fundamental uma análise sequencial da junta. Primeiramente deve-se verificar a pré-carga a ser aplicada no parafuso. Posteriormente, a determinação das rigidezes se faz necessária, uma vez que é importante precisar a parcela de cargas a serem aplicadas ao parafuso e aos membros. Por fim, mas não menos importante, há sempre a questão da fadiga em componentes que sofrem cargas alternadas. Evidentemente, em parafusos tal efeito não pode ser desprezado. 


\section{1}

\section{Determinação da Pré-Carga de Parafusos}

O termo pré-carga se refere ao carregamento em um parafuso imediatamente após ter sido apertado. Essa força gera uma tração no parafuso, induzindo à compressão nos membros.

A quantidade de pré-carga (carga residual) é crítica, uma vez que a junta pode falhar se a carga no parafuso é muito alta, muito baixa ou não uniforme em cada parafuso.

\section{Pré-carga Uniforme (Carga Residual)}

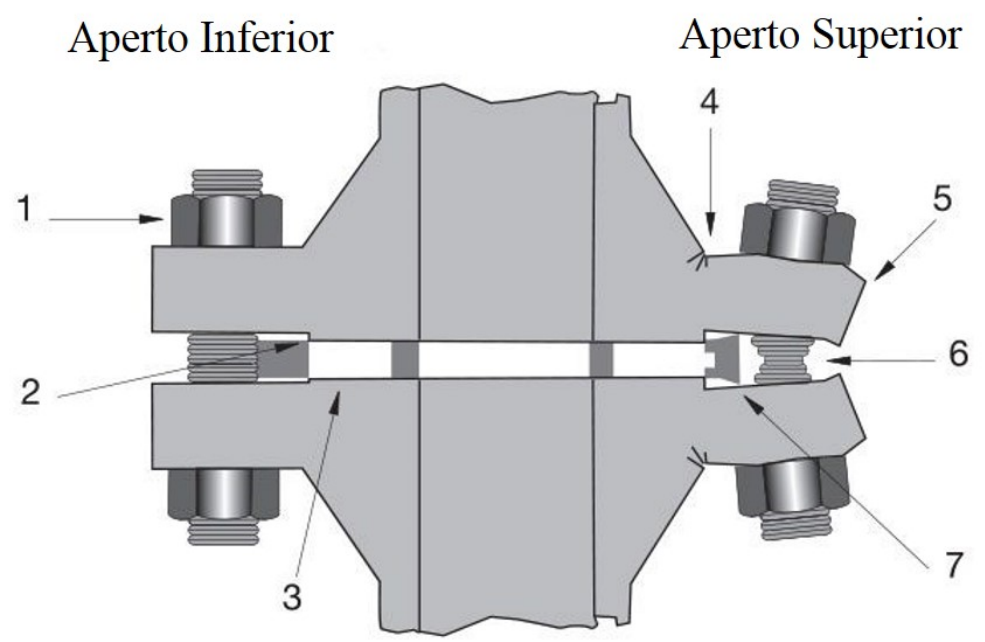

1. Parafuso se solta devido aos cicios de vibração da carga.

2. Danos na superficie da face de vedação.

3. Sem compressão.

4. Rachadura.

5. Rotação de Flange.

6. Produção de parafusos.

7. Excesso de compressão da gaxeta.

Figura 3.2: Tipos de pré-carga [3]

O dimensionamento de tal carga inicial tem como principais funções:

1. Garantir a força de aperto adequada durante a vida em serviço;

2. Atender a resistência do parafuso para a máxima carga externa de projeto;

3. Reduzir a amplitude dos ciclos alternados de tensão, aumentando a vida de fadiga do conjunto; 
4. Prevenir a separação da junta para cargas limites.

A força de pré-carga $F_{i}$ é controlada pelo torque $T$ de aperto por meio da relação empírica (3-1).

$$
F_{i}=\frac{5}{d} \cdot T
$$

Contudo, tal relação desconsidera fatores importantes, tais como variação do atrito na rosca. Dessa forma, essa relação deve ser determinada em função da distribuição das forças no parafuso. Essa distribuição é Normal (ou Gaussiana) e também depende do torque aplicado e do diâmetro nominal do parafuso. A relação (3-2), portanto, estabelece-se para uma pré-carga com um fator $\mathrm{R} \%$ de confiabilidade, além de um fator $\kappa_{R}$ que varia com a confiabilidade e com a característica da rosca.

$$
F_{i}(R \%)=\kappa_{R} \cdot \frac{1}{d} \cdot T
$$

A tabela 3.1 apresenta os valores do fator $\kappa_{R}$ para diferentes características e confiabilidades de acordo com a literatura.

Tabela 3.1: Variações do fator $\kappa_{R}$

\begin{tabular}{|c|c|c|}
\hline Confiabilidade (R) & $\kappa_{R}$ não-lubrificado & $\kappa_{R}$ lubrificado \\
\hline $50 \%$ & 5 & 5 \\
\hline $90 \%$ & 4 & 4.4 \\
\hline $99 \%$ & 3.3 & 4 \\
\hline $99,9 \%$ & 2.7 & 3.6 \\
\hline
\end{tabular}

É importante frisar também que a pré-carga aplicada deve ser próxima à carga de teste plena do parafuso. Essa carga é definida como a força de tração máxima que pode ser aplicada sem produzir uma deformação permanente. Com isso, define-se que a pré-carga "ideal"é

$$
F_{i}=K_{i} \cdot A_{t} \cdot S_{P}
$$

sendo $S_{P}$ a Resistência de Prova (tabelada), $A_{t}$ a área referente à tensão de tração da rosca (tabelada), e $K_{i}$ o fator de aperto, variando entre 0,75 e 1,0. Para aplicações corriqueiras envolvendo carregamento estático pode-se adotar $K_{i} \approx 0,9$. 


\section{2}

\section{Determinação da Rigidez de Juntas Aparafusadas}

Seguindo a modelagem clássica, deve-se analisar a junta aparafusada como conjunto de molas lineares. Essas molas possuem constantes do parafuso e dos membros da junta $k_{b}$ e $k_{m}$, respectivamente, e estão dispostas em paralelo. Por outro lado, ao analisar as rigidezes individuais, a associação é em série. Dessa forma tem-se que

$$
K=K_{\text {junta }}=k_{b}+k_{m}
$$

Pela lei de Hooke pode-se afirmar que

$$
\delta=\frac{\text { Força }}{\text { Rigidez }}
$$

sendo $\delta$ a deformação no parafuso e nos membros da junta.

Considerando que a deformações do parafuso e dos membros serão iguais, e que toda a carga externa $P$ aplicada vai para os dois elementos $\left(P_{b}\right.$ a carga que vai para o parafuso, e $P_{m}$ a carga que vai para os membros), conclui-se que

$$
\begin{gathered}
\frac{P_{b}}{k_{b}}=\frac{P_{m}}{k_{m}} \\
P=P_{b}+P_{m}
\end{gathered}
$$

Unindo as equações (3-6a) e (3-6b), afirma-se que

$$
\begin{gathered}
P_{b}=\underbrace{\left(\frac{k_{b}}{k_{b}+k_{m}}\right)}_{C} \cdot P=C \cdot P \\
P_{m}=\frac{k_{m}}{k_{b}+k_{m}} \cdot P=(1-C) \cdot P
\end{gathered}
$$

\subsection{1}

\section{Rigidez dos Parafusos}

A rigidez de um parafuso com alguma parte rosqueada dentro da zona de aperto geralmente consistirá em duas partes, segundo Shigley:

- $k_{t}$ referente à porção rosqueada;

- $k_{d}$ referente à porção não rosqueada.

Como a rigidez é equivalente à duas molas em série, tem-se que

$$
\frac{1}{K}=\frac{1}{k_{1}}+\frac{1}{k_{2}}+\ldots+\frac{1}{k_{n}}
$$


A rigidez do parafuso, portanto, é dada pela equação (3-9), onde $A_{t}$ é a área de tensão de tração (tabelada), $A_{d}$ é a área de diâmetro maior do fixador, e $L_{t}$ e $L_{d}$ são os comprimentos da parte rosqueada e não-rosqueada, respectivamente.

$$
K_{b}=\frac{E \cdot A_{d} \cdot A_{t}}{L_{d} \cdot A_{t}+L_{t} \cdot A_{d}}
$$

A figura 3.3 auxilia na visualização das dimensões utilizadas.

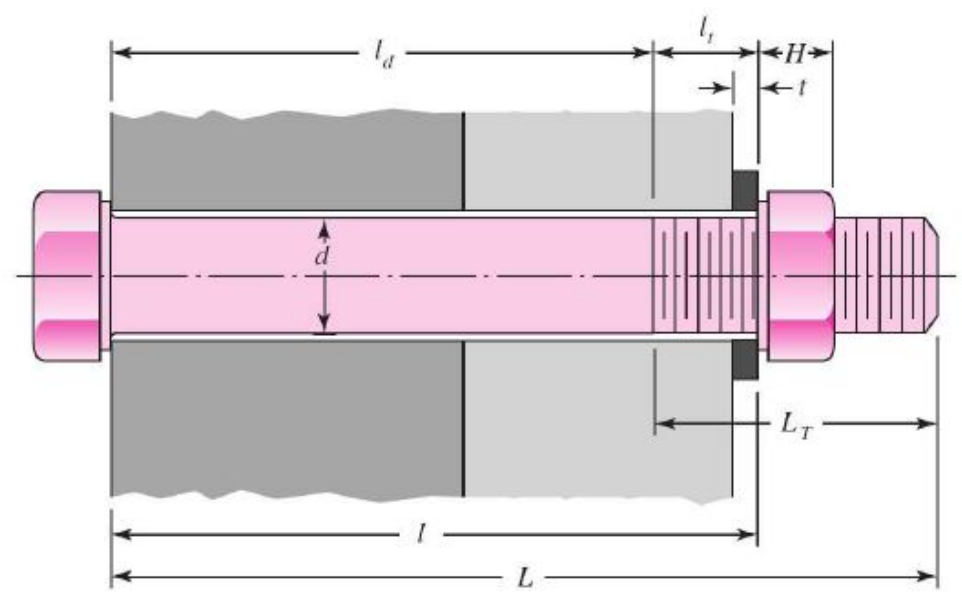

Figura 3.3: Dimensões sugeridas para desenvolver a determinação das rigidezes $[2]$

\subsection{2}

\section{Rigidez dos Membros}

A rigidez dos membros é uma tarefa mais complexa de se definir, uma vez que a distribuição não-uniforme das cargas não permite a definição de uma área uniforme. Assim, a rigidez dos membros acaba sendo determinada por experimentos. Contudo, diversos métodos de solução foram criados para buscar melhor previsibilidade de tais rigidezes. O mais conhecido e empregado, e que será aqui explicado, é o Método do Cone de Pressão de Rotscher, sugerido por Ito. A figura 3.4 ilustra melhor o cone aplicado à uma junta, cujo ângulo é constante de $2 \alpha$.

Os valores de $\alpha$ são muito discutidos, pois variam muito dentro da literatura. O primeiro valor utilizado foi de $\alpha=45^{\circ}$. Osgood, por sua vez, interpretou o ângulo como um intervalo de $25 \leqslant \alpha \leqslant 33^{\circ}$. Esse intervalo costuma representar bem os resultados, mas o valor dito como padrão é $\alpha=30^{\circ}$. 


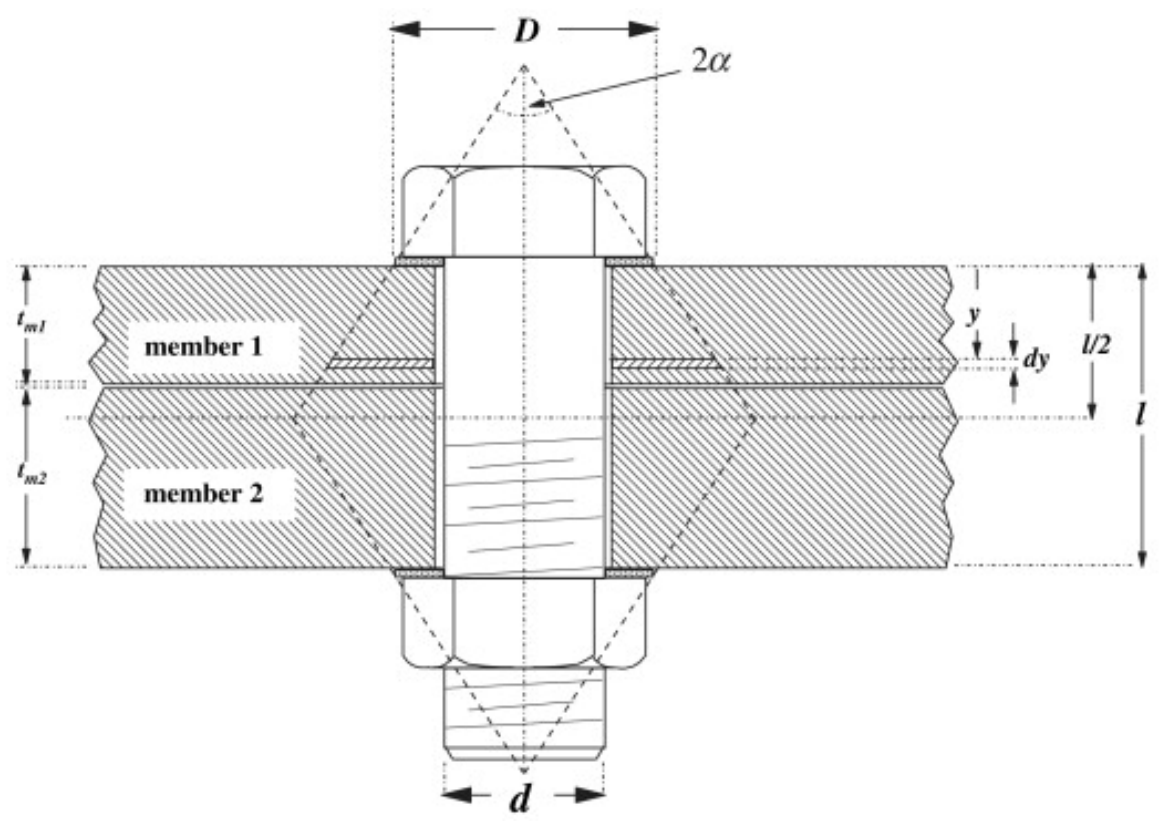

Figura 3.4: Método do cone de pressão [4]

Sendo $t_{0}$ a espessura do membro, $E_{0}$ o módulo de elasticidade do material do membro, e $D_{0}$ o diâmetro de aplicação da força, Williams et al. [4] afirma que

$$
k_{m i}=\frac{\pi \cdot E_{0} \cdot d \cdot \tan \alpha}{\ln \left[\frac{\left(2 \cdot t_{0} \tan \alpha+D_{0}-d\right) \cdot D_{0}+d}{\left(2 \cdot t_{0} \tan \alpha+D_{0}+d\right) \cdot D_{0}-d}\right]}
$$

Para fins explicativos, não julgou-se necessária a apresentação de todo o desenvolvimento para se obter a equação (3-10). Todo o desenvolvimento pode ser seguido nas referências $[2,6]$.

Deve-se recordar que, da mesma forma que o parafuso é subdividido, os membros também serão. Assim, a equação (3-8) é válida.

Para este presente trabalho, por sua vez, não será utilizado tal expressão. A aproximação utilizada será a de Juvinall [6]. Nela, só são considerados o diâmetro do parafuso, o módulo de elasticidade dos membros e o comprimento $l$ ocupado pelos membros. A relação é apresentada pela equação

$$
k_{m}=\frac{2 \cdot \pi \cdot d^{2} \cdot E}{l}
$$

As condições de contorno para uso dessa equação são:

1. Materiais iguais dos membros;

2. Furo central do mesmo diâmetro do parafuso; 
3. Diâmetro externo dos membros maior do que três vezes o diâmetro do parafuso.

O objetivo deste trabalho, bem como citado previamente, é verificar a validade deste método para outras condições de contorno, apresentadas a seguir no capítulo 4.

\section{3}

\section{Atuação de Forças Axiais}

Após se determinar uma pré-carga ao conjunto e verificar as rigidezes associadas, pode-se verificar a distribuição de forças axiais na junta. Deve-se recordar também que, conforme dito na seção 2.2, a junta, por definição, deve se manter unida. Contudo, ao se aplicar uma força com componente axial $P$, a junta segue sua tendência de se separar. Dessa forma, a equação (3-12) garante a condição de não separação dos elementos de junta.

$$
F_{i} \geqslant P_{m}
$$

A distribuição para cada membro ( $F_{b}$ no parafuso e $F_{m}$ nos membros) da força axial $P$ na junta pré-carregada com $F_{i}$ fica sob a seguinte forma

$$
\begin{gathered}
F_{b}=P_{b}+F_{i}=C \cdot P+F_{i} \\
F_{m}=P_{m}-F_{i}=(1-C) \cdot P-F_{i}
\end{gathered}
$$

\section{4}

\section{Fator de Carga}

Pelos conhecimentos básicos de Engenharia Mecânica, sabe-se que $\sigma=$ $\frac{F}{A}$. Aplicando esse conhecimento na equação (3-13a), tem-se que

$$
\sigma_{b}=\frac{C \cdot P}{A_{t}}+\frac{F_{i}}{A_{t}}
$$

O valor limite de $\sigma_{b}$ é a Resistência de Prova $S_{P}$. Para garantir segurança e confiabilidade no sistema, introduz-se um fator de carga $n$. Ao contrário do conceito de "fator de segurança $\varphi$ ", se $n>1$ então é possível assegurar que a tensão do parafuso é menor do que a resistência de prova.

$$
\begin{gathered}
\frac{C \cdot n \cdot P}{A_{t}}+\frac{F_{i}}{A_{t}}=S_{P} \\
n=\frac{S_{P} \cdot A_{t}-F_{i}}{C \cdot P}
\end{gathered}
$$




\section{5}

\section{Fadiga de Parafusos}

A maior questão do projeto de fadiga de juntas aparafusadas é a distribuição de cargas na seção rosqueada, além das tensões atuantes. Para o projeto de parafuso, é interessante que seja utilizado o método SN, cujas cargas não deformam o elemento. Isso é sensato a partir do momento em que todas as cargas aplicadas são abaixo da pré-carga, que por sua vez são abaixo dos limites de resistência. A equação (3-17) utilizada é a de Goodman e considera um fator de segurança $\varphi$.

$$
\frac{\sigma_{a}}{S_{e}}+\frac{\sigma_{m}}{S_{u t}}=1 / \varphi
$$

Para verificar as tensões, é importante revisar como analisar e identificar cada uma. A figura

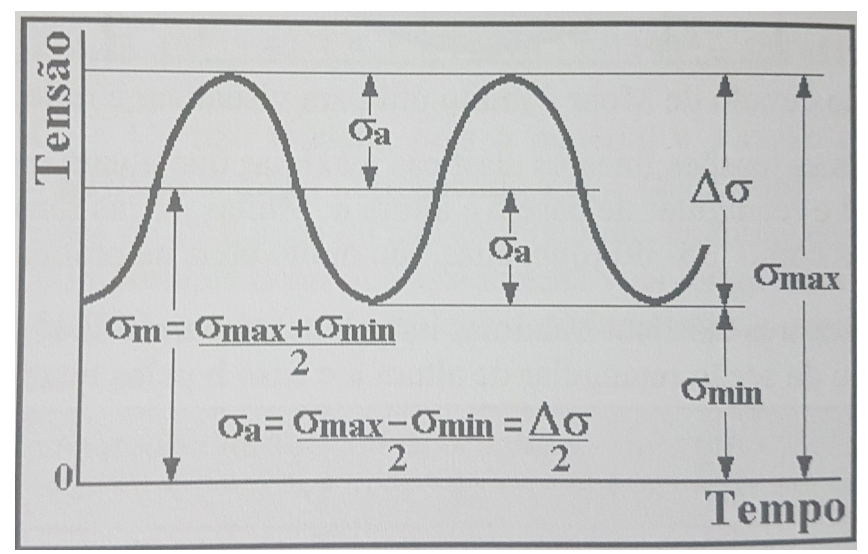

Figura 3.5: Definição de cargas para fadiga [5]

Segundo Juvinall [6], podemos definir as tensões acima como

$$
\begin{gathered}
\sigma_{a}=\frac{F_{b}-F_{i}}{2 \cdot A_{t}}=C \cdot \frac{P}{2 \cdot A_{t}} \\
\sigma_{m}=\sigma_{a}+\frac{F_{i}}{A_{t}}=C \cdot \frac{P}{2 \cdot A_{t}}+\frac{F_{i}}{A_{t}}
\end{gathered}
$$

Contudo, os testes a serem realizados, conforme também será explicado nos capítulos 5 e 7, os testes serão realizados entre cargas não necessariamente acima da pré-carga, nem tampouco variando entre 0 e um valor máximo. Dessa forma, deve-se analisar a Fadiga pelo critério de Goodman utilizando as seguintes definições:

$$
\begin{aligned}
\sigma_{a} & =\frac{F_{\text {max }}-F_{\text {min }}}{2 \cdot A_{t}} \\
\sigma_{m} & =\frac{F_{\text {max }}+F_{\text {min }}}{2 \cdot A_{t}}
\end{aligned}
$$


Importante recordar que a resistência à Fadiga para vida infinita $S_{e}$ é calculada sob as seguintes equações

$$
\begin{gathered}
S_{e}{ }^{\prime}=\left(0,566-9,68 \cdot 10^{-5} \cdot S_{u t}\right) \cdot S_{u t} \\
S_{e}=\underbrace{k_{a}}_{\text {acabamento }} \cdot \underbrace{k_{b}}_{\text {tamanho }} \cdot \underbrace{k_{c}}_{\text {carga }} \cdot \underbrace{k_{\theta}}_{\text {temperatura }} \cdot \underbrace{k_{e}}_{\text {confiabilidade }} \cdot \underbrace{k_{f}}_{\text {variados }} \cdot S_{e}{ }^{\prime}
\end{gathered}
$$

\section{6}

\section{Gráfico de decomposição de carga externa}

Um diagrama de união para junções aparafusadas pode ser representado sob a seguinte forma.

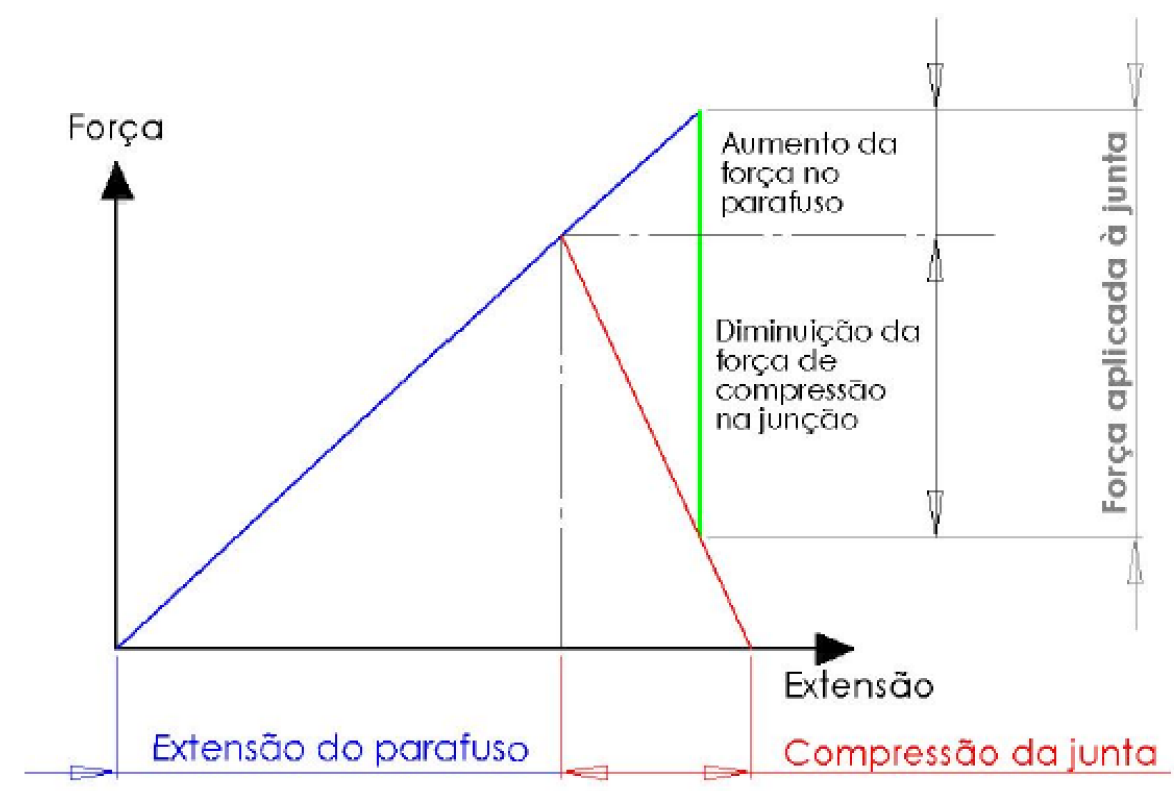

Figura 3.6: Efeitos existentes em um diagrama de junção

Com esses diagramas, fica simples a identificação de uma junta dita como "dura"ou "macia". A junta "dura"é montada com um parafuso de baixa rigidez com uma junção de rigidez elevada. Assim, o parafuso sustentará somente uma pequena porção da força aplicada. Por outro lado, em juntas "macias", a rigidez elevada é associada ao parafuso, e a junção apresenta baixa rigidez. Com isso, o parafuso sustentaria a maioria da força externa aplicada. A figura 3.8 consegue representar bem a relação aqui explicitada. 


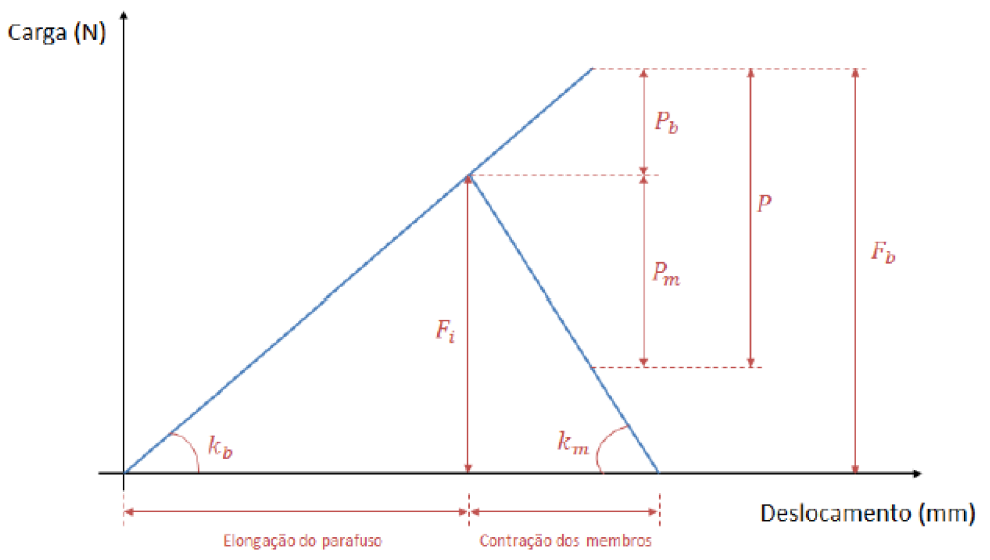

Figura 3.7: Variáveis empregadas para construção de um diagrama de junção
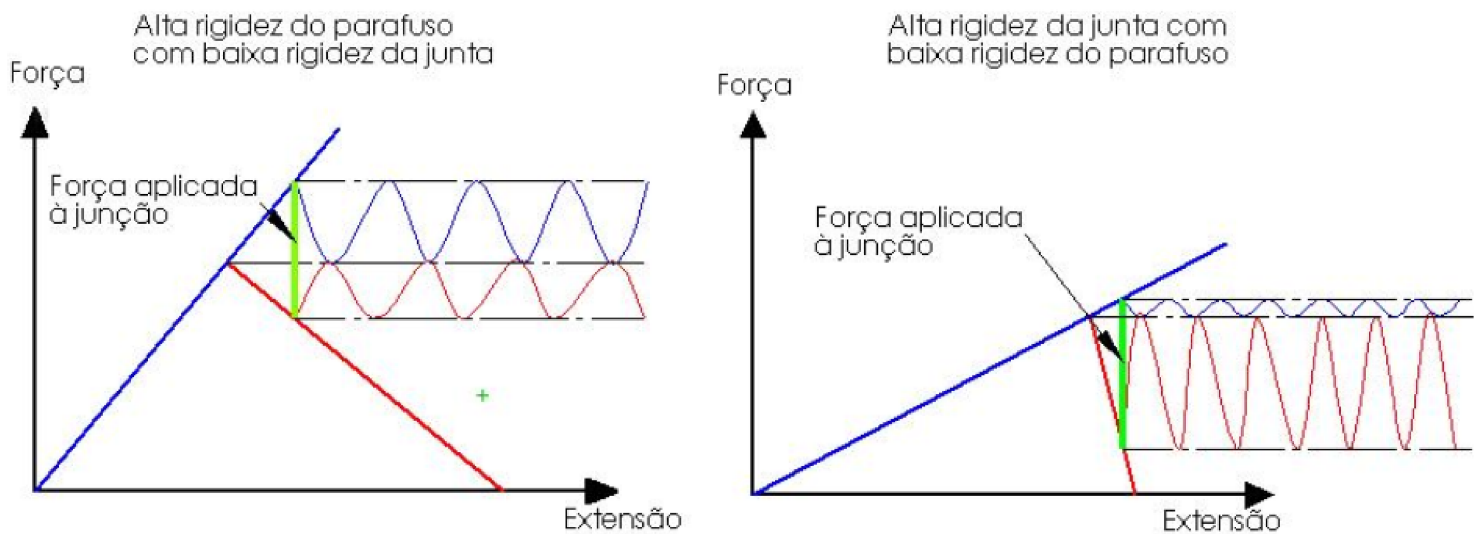

Figura 3.8: Rigidezes relativas

Uma outra visualização importante deste diagrama é verificá-lo com a presença de uma pré carga $\left(F_{i}\right)$. A figura 3.9 apresenta tal fato. Nota-se de maneira similar as variações citadas anteriormente, bem como as inclinações.

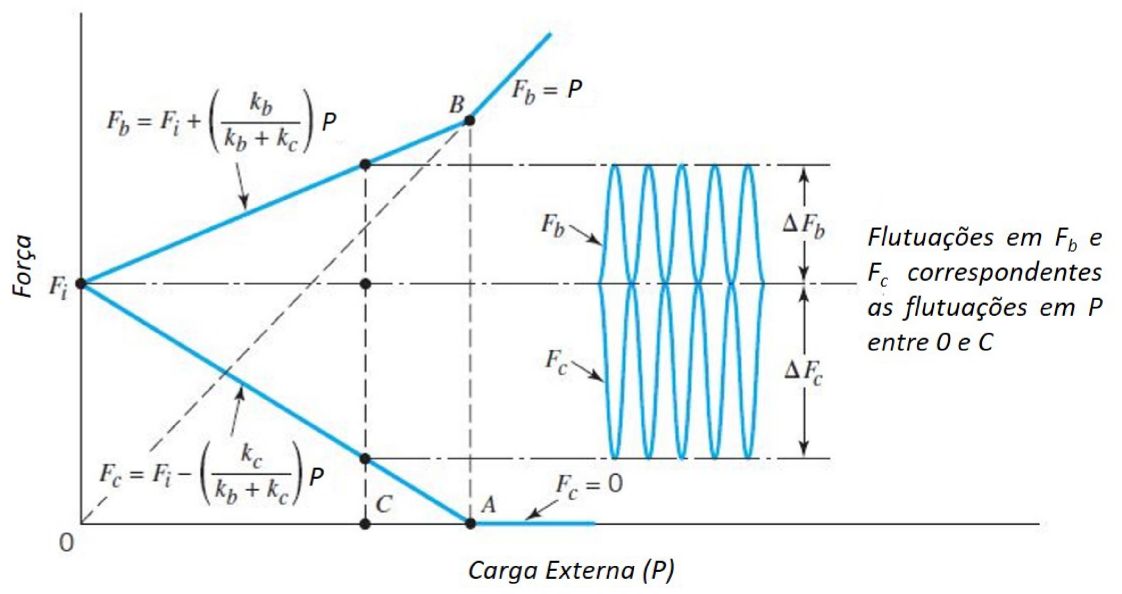

Figura 3.9: Relações entre as forças atuantes em uniões aparafusadas [6] 


\section{Corpo de Prova}

Para a definição do corpo de prova e suas propriedades, seguiu-se a norma ISO 898-1:2013 [12]. Com intuito de melhor visualização dos efeitos, escolheu-se usar um parafuso mais robusto em termos de dimensões. Dessa forma, pode-se analisar de maneira macroscópica os efeitos, além de facilitar toda a montagem dos experimentos, descritos no capítulo 6.

O parafuso utilizado foi um Allen métrico M20, com passo de 2,5 mm (rosca grossa) e comprimento de $200 \mathrm{~mm}$. A figura 4.1 mostra o parafuso utilizado.

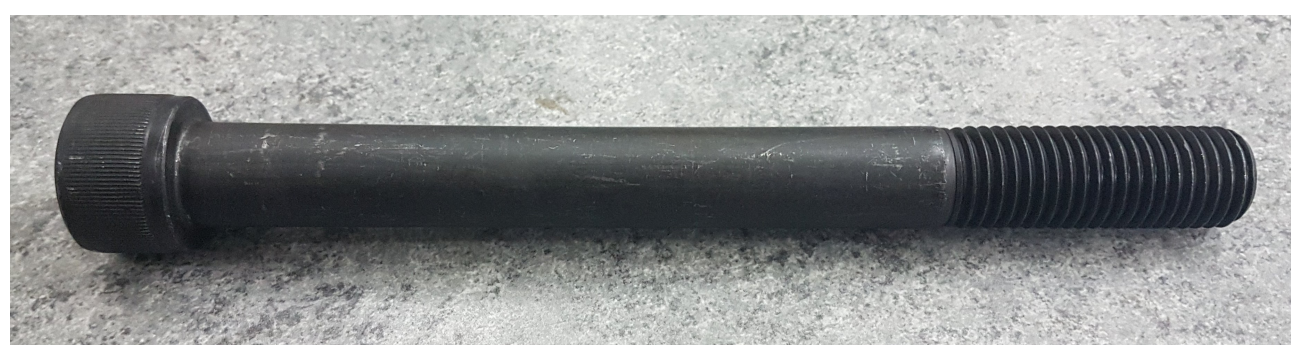

Figura 4.1: Parafuso M20 utilizado como corpo de prova

A classe de resistência escolhida foi 12.9, então podemos afirmar que seu material é uma liga de aço, temperado e revenido. Isso significa que possui alta resistência e aplicabilidade em sustentações pesadas. A cabeça do parafuso escolhido é mostrada na figura 4.2, e podemos verificar a classe do parafuso, conforme citado no capítulo 2.

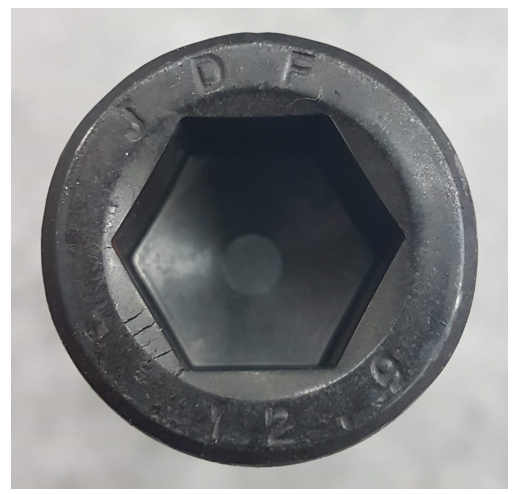

Figura 4.2: Cabeça do parafuso M20 utilizado

A partir desses dados e dos conhecimentos detalhados no capítulo 1, pode-se elaborar a tabela $4.1 \mathrm{com}$ o resumo das características do parafuso utilizado. 
Tabela 4.1: Características do Corpo de Prova utilizado

\begin{tabular}{|lccc|}
\hline \multicolumn{4}{|c|}{ Características do Parafuso M20 classe $\mathbf{1 0 . 9}$} \\
\hline Diâmetro maior nominal & $d$ & 20 & $\mathrm{~mm}$ \\
\hline Passo & $p$ & 2,5 & $\mathrm{~mm}$ \\
\hline Comprimento & $L$ & 200 & $\mathrm{~mm}$ \\
\hline Comprimento da rosca & $L_{T}$ & 52 & $\mathrm{~mm}$ \\
\hline Diâmetro menor & $d_{r}$ & 16,93 & $\mathrm{~mm}$ \\
\hline Diâmetro de passo & $d_{p}$ & 18,37 & $\mathrm{~mm}$ \\
\hline Área de tensão de tração & $A_{t}$ & 245 & $\mathrm{~mm}^{2}$ \\
\hline Área de diâmetro menor & $A_{r}$ & 225 & $\mathrm{~mm}^{2}$ \\
\hline Resistência mínima de prova & $S_{P \min }$ & 970 & $\mathrm{MPa}$ \\
\hline Resistência mínima de tração & $S_{u t \min }$ & 1220 & $\mathrm{MPa}$ \\
\hline Resistência mínima de escoamento & $S_{y_{\min }}$ & 1110 & $\mathrm{MPa}$ \\
\hline Carga de Prova & $F_{P}$ & 245 & $\mathrm{kN}$ \\
\hline
\end{tabular}

Importante frisar que a carga de prova é calculada com a área de tensão de tração nominal, conforme a norma [12].

Os dados da tabela 4.1 foram retirados das referências clássicas $[2,6,10$, 11]. Os valores verificados do corpo de prova utilizado são muito próximos aos valores obtidos das tabelas, portanto, assumiram-se esses valores para efeitos de contas futuras.

Além do parafuso utilizado, foram utilizadas 4 bolachas de aço para simular os membros da junta. A figura 4.3 e a tabela 4.2 apresentam esses elementos.

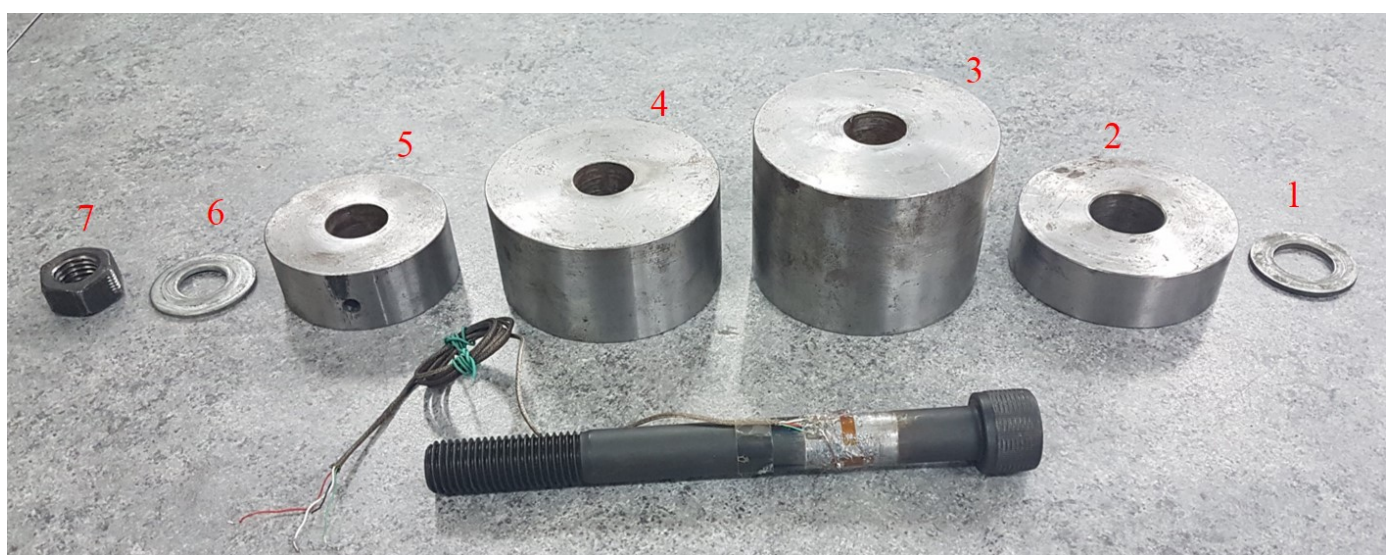

Figura 4.3: Elementos utilizados para elaboração do procedimento experimental 
Tabela 4.2: Dimensões dos elementos constituintes da junta

\begin{tabular}{|c|c|c|c|c|}
\hline Item & Elemento & Altura & Diâmetro Externo & Diâmetro Interno \\
\hline 1 & Arruela & $3,0 \mathrm{~mm}$ & $43,4 \mathrm{~mm}$ & $25,4 \mathrm{~mm}$ \\
\hline 2 & Bolacha & $28,0 \mathrm{~mm}$ & $90,0 \mathrm{~mm}$ & 30,0 \\
\hline 3 & Bolacha & $70,0 \mathrm{~mm}$ & $100,0 \mathrm{~mm}$ & $25,4 \mathrm{~mm}$ \\
\hline 4 & Bolacha & $50,0 \mathrm{~mm}$ & $100,0 \mathrm{~mm}$ & $25,4 \mathrm{~mm}$ \\
\hline 5 & Bolacha & $30,0 \mathrm{~mm}$ & $75,0 \mathrm{~mm}$ & $25,4 \mathrm{~mm}$ \\
\hline 6 & Arruela & $3,0 \mathrm{~mm}$ & $43,4 \mathrm{~mm}$ & $20,5 \mathrm{~mm}$ \\
\hline 7 & Porca & $15,3 \mathrm{~mm}$ & $29,4 \mathrm{~mm}$ & $15,3 \mathrm{~mm}$ \\
\hline
\end{tabular}

\section{1}

\section{Rigidezes}

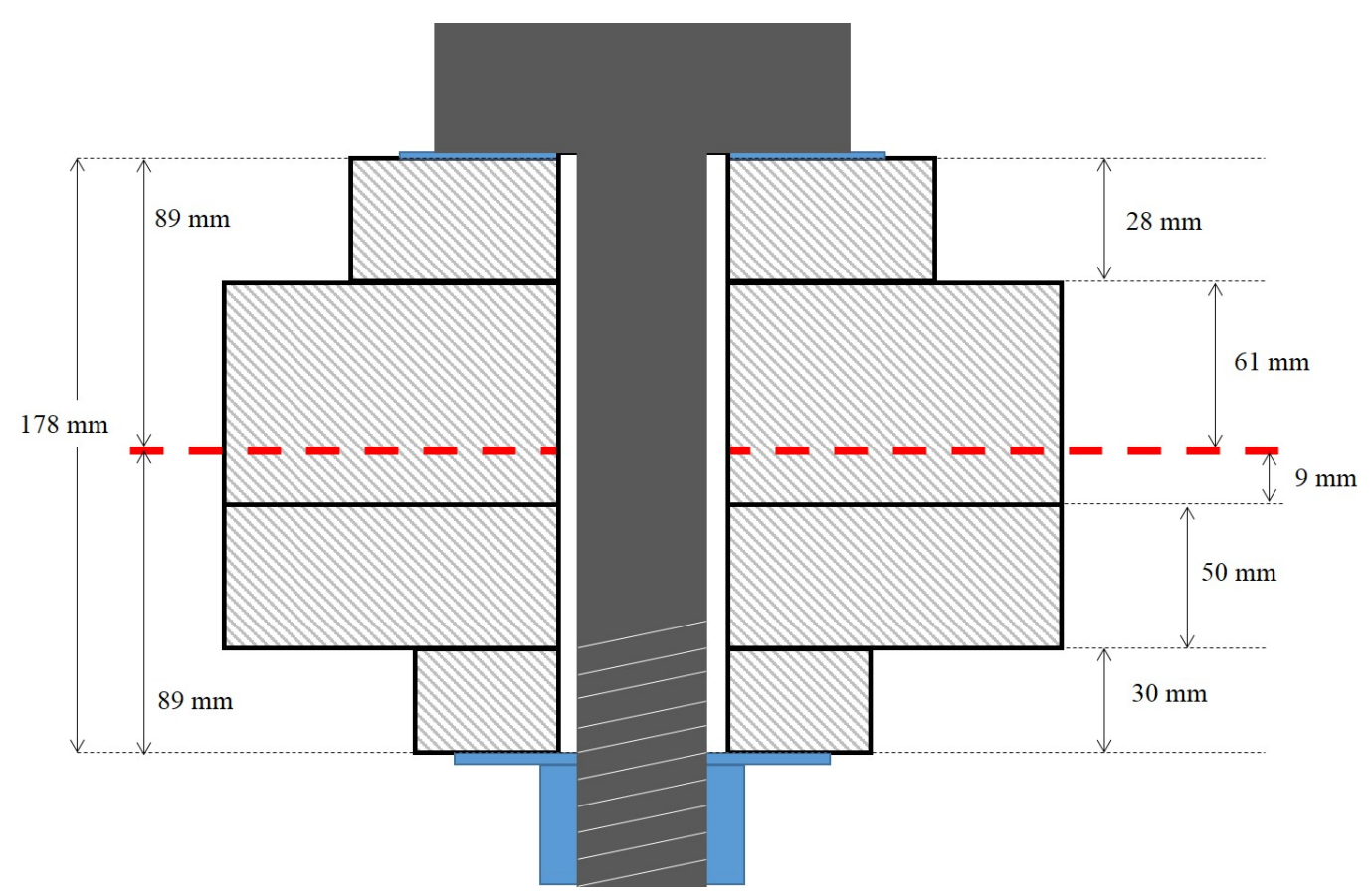

Figura 4.4: Junta aparafusada a ser analisada

\subsection{1}

\section{Rigidez do Parafuso}

Para calcular a rigidez do parafuso é necessário retornar à equação (3-9). De posse da equação e da imagem 4.4 acima com os comprimentos citados, pode-se calcular tal rigidez na equação (4-1).

$$
k_{b}=\frac{E \cdot A_{d} \cdot A_{t}}{L_{d} \cdot A_{t}+L_{t} \cdot A_{d}}=\frac{205 \times 10^{9} \cdot 314 \times 10^{-6} \cdot 245 \times 10^{-6}}{\left(0.148 \cdot 245 \times 10^{-6}\right)+\left(0.052 \cdot 314 \times 10^{-6}\right)}
$$




$$
k_{b}=0.3018 \times 10^{6} \mathrm{~N} / \mathrm{mm}
$$

\subsection{2}

\section{Rigidez dos Membros}

Conforme citado na seção 3.2.2, utilizou-se a proposição de Juvinall. Dessa forma, recorda-se a equação (3-11) e obtém-se o resultado, apresentado na equação (4-2).

$$
\begin{gathered}
k_{m}=\frac{2 \cdot \pi \cdot d^{2} \cdot E}{l}=\frac{2 \cdot \pi\left(20 \times 10^{-3}\right) \cdot 205 \times 10^{9}}{0.198} \\
k_{m}=2.60 \times 10^{6} \mathrm{~N} / \mathrm{mm}
\end{gathered}
$$

\subsection{3}

\section{Rigidez da Junta}

Conforme apresentado na seção 3.2, a rigidez da junta é dada pela equação (3-4). Dessa forma, tem-se que

$$
\begin{gathered}
K=k_{b}+k_{m}=2.90 \times 10^{6} \mathrm{~N} / \mathrm{mm} \\
C=\frac{k_{b}}{k_{b}+k_{m}}=10,4 \%
\end{gathered}
$$




\section{Métodos Revisados}

Neste capítulo será tratada a metodologia dos testes experimentais. Sobretudo, serão avaliadas as entradas e saídas de cada tipo de teste, bem como suas variáveis, e as relações impostas para que atinjam-se os objetivos. Após isso, os cálculos de limites do parafuso e dos equipamentos são expostos também. Os testes de tração e fadiga necessitaram de uma máquina de tração, enquanto o teste de torque não. Os três testes, por sua vez, foram realizados com um aparelho para determinar as deformações no parafuso.

\section{1}

\section{Teste de Torque}

Para poder comprovar a equação 3-2, necessita-se avaliar quais variáveis são disponíveis e como é possível definir-las. Percebe-se que, dessa equação, o valor de torque pode ser verificado com auxílio de um torquímetro, porém o valor da força da pré-carga $F_{i}$ não pode ser lido diretamente. Dessa forma, necessita-se relacionar essa força às leituras extensométricas pela lei de Hooke, dada abaixo. A relação, portanto, passa a ser dada na equação (5-2).

$$
\begin{gathered}
\sigma=E \cdot \varepsilon \\
\sigma=F / A \\
F_{i}=\underbrace{\left(E \cdot A_{t}\right)}_{\text {constantes }} \cdot \underbrace{\varepsilon}_{\text {leitura }}
\end{gathered}
$$

Contudo, não adianta somente verificar tal relação sem avaliar o limite do parafuso. O torque máximo é fornecido pela equação (3-3) com $K_{i}=1(100 \%)$, isto é

$$
F_{y}=100 \% \cdot A_{t} \cdot \underbrace{S_{P}}_{970 \mathrm{MPa}}=237,5 k N \approx 24 \text { ton }
$$

Seguindo a equação empírica (3-1), o torque máximo, por sua vez, é de 949,86 N.m. Deve-se ficar atento para não passar desse valor para não romper a rosca do parafuso ou da porca. 


\section{2}

\section{Teste de Tração}

No teste de tração serão aplicadas entradas em uma máquina servohidráulica por meio de degraus. Haverá a aplicação de uma pré-carga determinada pelo torque,caracterizando-se, portanto, uma junta aparafusada de tração.

Da mesma forma que no teste de torque, é fundamental determinar os limites do parafuso. Para esse caso, deve-se verificar a carga de escoamento $\left(F_{y}\right)$ e a carga de rompimento do parafuso $\left(F_{u t}\right)$.

$$
\begin{aligned}
& F_{y}=A_{t} \cdot \underbrace{S_{y}}_{1100 \mathrm{MPa}}=269,3 k N \approx 27 \text { ton } \\
& F_{u t}=A_{t} \cdot \underbrace{S_{u t}}_{1220 \mathrm{MPa}}=298,7 k N \approx 30 \text { ton }
\end{aligned}
$$

De posse dos valores das rigidezes obtidos em 4.1, e da pré-carga dada ao parafuso, estima-se a deformação que o parafuso recebe. Esse resultado é comparado com a deformação efetiva sofrida, que será lida pelo equipamento de aquisição de dados. A comparação é feita segundo a equação abaixo.

$$
\sigma_{b}=\varepsilon_{b} \cdot E=\frac{C \cdot P+F_{i}}{A_{t}} \Rightarrow \underbrace{\varepsilon_{b}}_{\text {leitura }}=\frac{\left(\frac{k_{b}}{k_{b}+k_{m}}\right) \cdot P+F_{i}}{A_{t} \cdot E}
$$

Dessa forma, será possível verificar se a aproximação de Juvinall apresentada anteriormente também é válida para essas condições de contorno existentes.

\section{3}

\section{Teste de Fadiga}

O teste de fadiga, por sua vez, irá manter continuar com os resultados de $k_{b}$ e $k_{m}$ obtidos em 5.2. Com isso, pode-se obter as tensões de amplitude e média, respectivamente $\sigma_{a}$ e $\sigma_{m}$. Da literatura se obtém $S_{u t}$, e então pode-se estimar a Resistência à Fadiga $S_{e}$ na condição limite $(\varphi=1)$. Ele sugere que o valor de $S_{e}$ para parafusos M1.6-M36 de classe ISO 12.9 seja de $190 \mathrm{MPa}$.

Evidente que, ao se estimar o $S_{e}$, deve-se fixar $S_{e}{ }^{\prime}$ e os fatores modificadores, com exceção do fator de concentração de tensões. Parafusos, por possuírem filetes e roscas, têm seu valor tabelado de $k_{e}$. O outro objetivo deste teste é verificar, para o valor da literatura de Shigley citado anteriormente de $S_{e}$, qual o $k_{e}$ para essa classe de parafuso. 
Para a determinação desses resultados, foram estabelecidas as cargas máxima e mínima, respeitando as definições de tensões apresentadas a seguir.

$$
\begin{aligned}
\sigma_{a} & =\frac{F_{\text {max }}-F_{\text {min }}}{2 \cdot A_{t}} \\
\sigma_{m} & =\frac{F_{\text {max }}+F_{\text {min }}}{2 \cdot A_{t}}
\end{aligned}
$$

A comparação será realizada por meio da equação

$$
S e=\frac{\sigma_{a}}{1-\frac{\sigma_{m}}{S_{u t}}}
$$




\section{6 \\ Dados Experimentais}

Para um experimento ser bem sucedido, deve-se compreender o objetivo dos testes e os métodos a serem aplicados. Os três testes realizados seguiram o proposto no capítulo 5 com os corpos de prova apresentados no capítulo 4 .

\section{1}

\section{Equipamentos e Materiais}

Para a realização dos experimentos, utilizaram-se os seguintes equipamentos:

- Máquina servohidráulica com capacidade de 1000 kN em carga dinâmica e 1200 kN em carga estática;

- Célula de carga

- Garras triangulares de 25-44mm

- Parafuso M20x2,5x200mm classe 12.9

- Bolachas de aço (juntas a serem aparafusadas)

- Torquímetro com capacidade para até 300 N.m

- Máquina para leitura extensométrica (aquisição de dados)

\section{2}

\section{Preparação do Experimento}

Nesta seção será apresentada a montagem da bancada experimental e de seus componentes, isto é, a preparação do corpo de prova com sua instrumentação, a preparação das juntas.

\subsection{1}

Juntas

As 4 bolachas utilizadas possuíam originalmente $21 \mathrm{~mm}$, ou seja, somente 0,5mm de tolerância entre o corpo do parafuso e as bolachas. Com os strain gages colados e o fio saindo do terminal, evidentemente esses furos se mostraram menores que o necessário. Alargou-se então os furos para 1 polegada $(25,4 \mathrm{~mm})$, de forma a ficar sem interferência e não comprometer o experimento.

A bolacha número 5 (ver Capítulo 4), por ser a menor, recebeu um furo de $6 \mathrm{~mm}$ passante de um lado para permitir a saída do fio. Poderia ser feito um rasgo na parte superior da peça também, mas o furo foi a melhor solução sem que alterasse consideravelmente a estrutura. 


\section{2 .2}

\section{Parafuso}

Antes de utilizar o corpo de prova conforme descrito no capítulo 4, precisou-se fazer um pequeno rebaixo no torno para a colagem do strain gage. Esse rebaixo tem a intenção de evitar danos ao extensômetro quando o mesmo for acoplado às juntas. A figura 6.1 mostra como ficou o parafuso após realizado o rebaixo.



Figura 6.1: Parafuso com rebaixo

Poderia ser feito um furo na parte inferior da cabeça do parafuso para passar os fios, porém não é convencional realizar tal procedimento, uma vez que é extremamente arriscado e complexo. A solução mais viável encontrada foi adaptar uma passagem pelas bolachas, conforme descrito na seção 6.2.1.

Para melhorar o acabamento, a área rebaixada foi lixada para remover maiores asperezas. Ressalta-se a importância de ter sempre alguma aspereza para facilitar a colagem do strain gage futuramente, porém não pode ser tamanha a ponto de alterar a leitura ou danificar o extensômetro.

\section{2 .3}

\section{Instrumentação}

Foram utilizados 4 Strain Gages da Micro-Measurements (MM), modelo CEA-06-125UE. Segundo o datasheet presente na embalagem, tais strain gages possuem, à $24^{\circ} \mathrm{C}$, Resistência de $120.0 \Omega \pm 0.3 \%$, Gage Factor $2.070 \pm 0.5 \%$, e Fator de Concentração de Tensões $\left(K_{t}\right)(+0.9 \pm 0.2) \%$. Informações sobre dimensões e ilustrações do extensômetro utilizado encontram-se na figura 6.2 abaixo.

\begin{tabular}{|c|c|c|c|c|c|}
\hline \multirow[t]{2}{*}{ 125UE } & ח & CEA & 120,350 & 0.125 & 3.18 \\
\hline & actual size & \multicolumn{4}{|c|}{$\begin{array}{l}\text { General-purpose gage with large tab at each end of grid. Exposed solder tab } \\
\text { area } 0.08 \times 0.07 \text { in }(2.0 \times 1.8 \mathrm{~mm}) \text {. } \\
\text { Matrix size: } 0.57 \mathrm{~L} \times 0.20 \mathrm{~W} \text { in. }(14.5 \mathrm{~L} \times 5.1 \mathrm{~W} \mathrm{~mm})\end{array}$} \\
\hline
\end{tabular}

Figura 6.2: Datasheet do Strain Gage utilizado - MM CEA-06-125UE 
A disposição escolhida foi uma Ponte de Wheatstone completa, conforme ilustração da figura 6.3. Essa disposição atende à necessidade de verificar as deformações em duas direções perpendiculares (deformações axial e longitudinal) ao longo de lados opostos do parafuso.

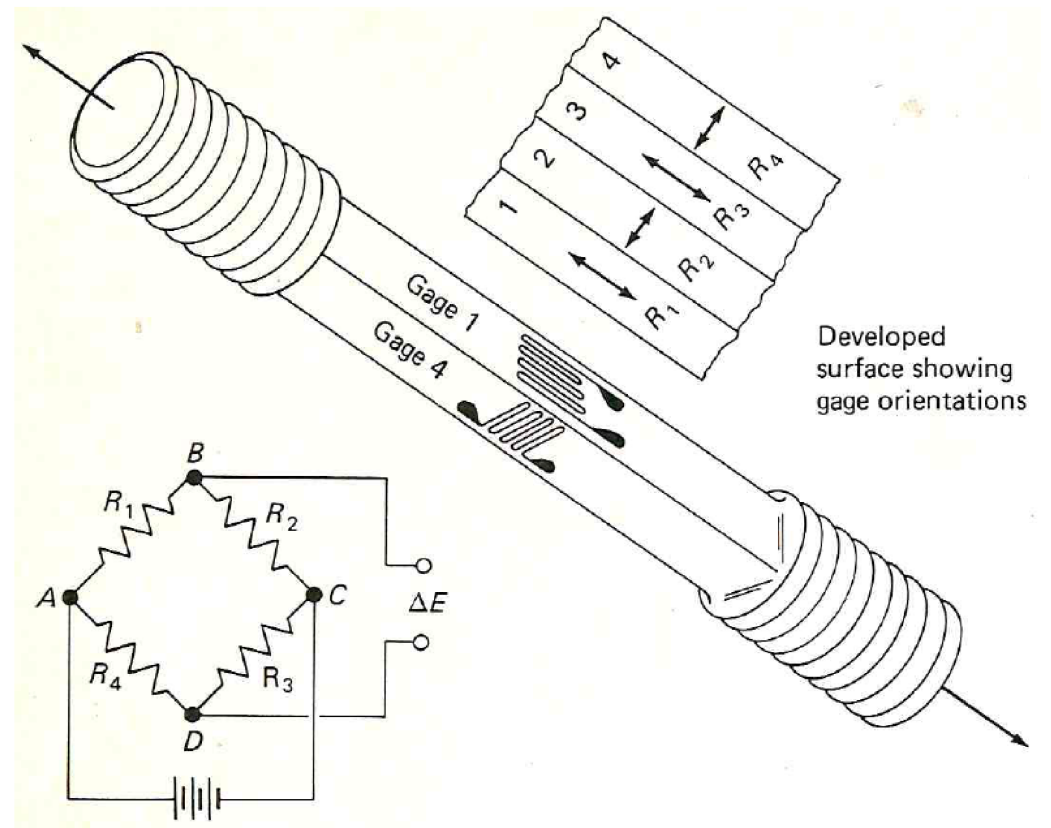

Figura 6.3: Disposição dos strain gages ao longo do corpo de prova e sua respectiva ponte de Wheatstone - [7]

A figura 6.4 mostra como ficaram os strain gages colados, conforme a figura 6.3.

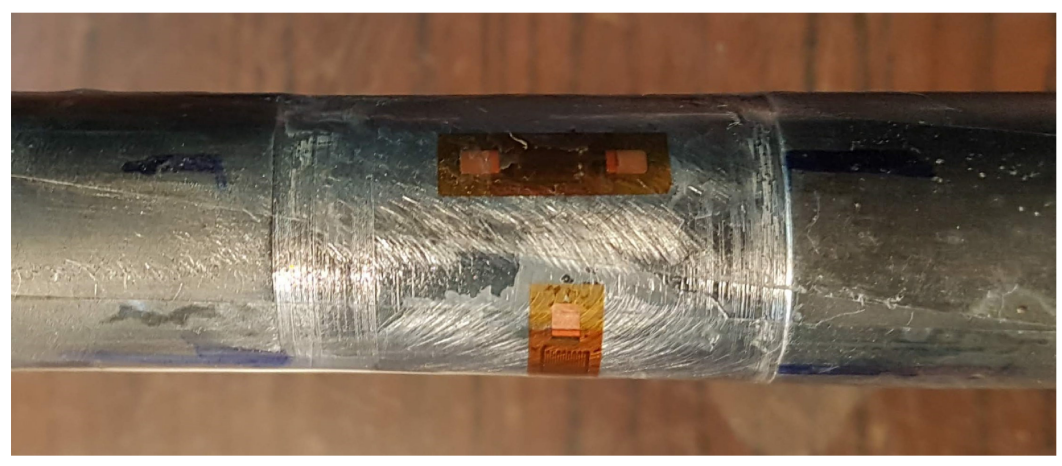

Figura 6.4: Parafuso com os strain gages colados

A figura 6.5 apresenta os dois últimos passos da instrumentação do parafuso. A figura 6.5(a) são os strain gages conectados entre si e entre os terminais, conforme a ilustração da figura 6.3. Por fim, a figura 6.5(b) já contém as conexões com o fio para realizar o fornecimento e a medição entre pontos de voltagem. Os fios preto e vermelho são os pontos de fornecimento de carga entre os pontos $\mathrm{A}-\mathrm{C}$, enquanto os fios verde e branco medem a voltagem entre os pontos B-D. 




6.5(a): Strain Gages conectados ao terminal

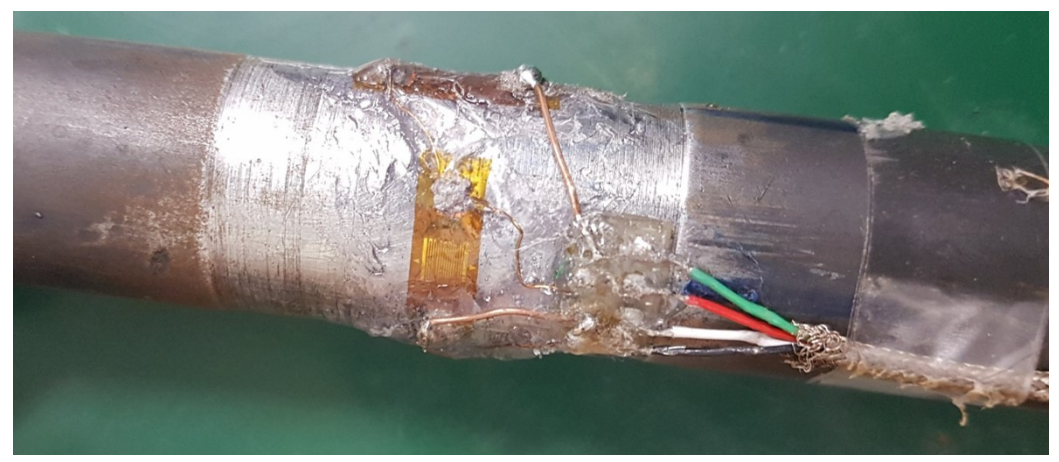

6.5(b): Terminais conectados aos fios

Figura 6.5: Conexões finais dos strain gages

Para reforçar os contatos, utilizou-se um silicone específico. Este silicone oferece uma proteção química e física ao esmalte dos contatos, não só contra contaminação, mas também contra poeira e umidade, além de dar sustentação mecânica adicional. Na hora do teste, para garantir maior segurança, envolveuse a área rebaixada com fita isolante, de forma à qualquer tipo de contato não provocar danos elétricos ou mecânicos.

\section{3}

\section{Métodos Empregados}

Os primeiros testes são testes de torque e força no parafuso. Os segundos serão testes estáticos e dinâmicos, cujo objetivo principal é a verificação de quanto da carga está indo para o parafuso e quanto está indo para descarregas as bolachas.

Com uma pré-carga, carregam-se as bolachas e verifica-se quanto da carga está indo para o parafuso e quanto está indo para aliviar as bolachas. Comparar com as contas. Isso fornecerá o ângulo $\alpha$ aproximado que buscamos (objetivo do trabalho).

Um cuidado tomado é com as cargas que estão indo para o parafuso, no sentido de verificar se não existem trincas nas roscas do parafuso. Uma vez que isso tenha iniciado, os resultados tornam-se irregulares, pois já houve início da 
falha por fadiga do componente.

\section{4}

\section{Aquisição de Dados}

O procedimento para aquisição de dados não foi muito sofisticado, apesar de ter sido muito preciso. O equipamento utilizado foi o P3 Strain Indicator and Recorder da Vishay. Para o teste estático, não foi necessário armazenar os valores, sendo necessário somente realizar uma leitura no instante correto. No teste dinâmico, por sua vez, era importante ter os dados armazenados. O equipamento possui um software para instalação em computador, o que permite a visualização e o armazenamento em tempo real.

Contudo, a aquisição é de um valor por segundo. Portanto, para as medidas dinâmicas, a aquisição acabou sendo um fator limitante. 


\section{Resultados e Discussões}

A seguir, apresentam-se os resultados obtidos dos testes conforme as metodologias descritas no capítulo 5 .

\section{1}

\section{Teste de Torque}

Nesse teste, o parafuso foi montado em uma morsa pela cabeça. A porca estava na outra extremidade, o que permitiu seu aperto. A figura 7.1 apresenta como foi montado o experimento junto ao leitor de deformação.

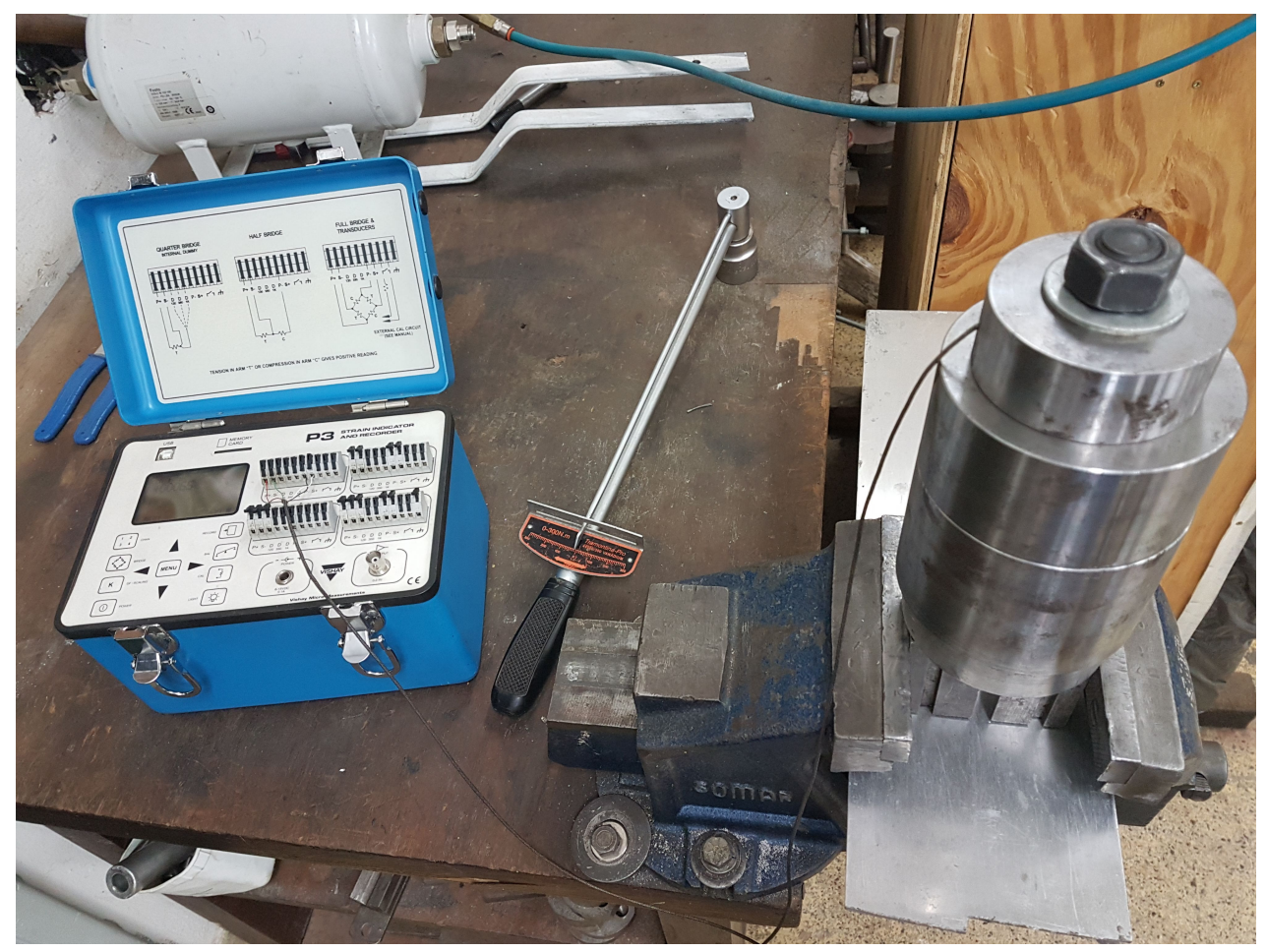

Figura 7.1: Teste para verificar relação Torque $T$ e Força de Pré-carga $F_{i}$

Os resultados do teste de torque são valores de Torque aplicado $(T)$ com uso do torquímetro e de deformação $(\varepsilon)$, relacionados pela equação (3-2) e pela tabela 3.1. As tabelas 7.1 e 7.2 apresentam, respectivamente, os resultados de deformação lida e torque calculado. O gráfico 7.2, por sua vez, reúne os resultados das tabelas anteriores. Os valores teóricos de deformação foram calculados com as equações (5-2) e (3-2). Foram utilizados dois valores para comparação: o mais conservador e mais utilizado $\mathrm{R}=50 \% \kappa=5$ e $\mathrm{R}=99 \%$ $\kappa=3.3$ 
Tabela 7.1: Resultados de Deformação em função do Torque aplicado

\begin{tabular}{|c|c|c|c|}
\hline Torque & $\begin{array}{c}\text { Deformação } \\
\text { Experimental }\end{array}$ & $\begin{array}{c}\text { Deformação } \\
\mathbf{R}=\mathbf{5 0 \%}\end{array}$ & $\begin{array}{c}\text { Deformação } \\
\mathbf{R}=\mathbf{9 9 \%}\end{array}$ \\
\hline 20 N.m & $100 \mu \varepsilon$ & $99,6 \mu \varepsilon$ & $79,7 \mu \varepsilon$ \\
\hline 40 N.m & $169 \mu \varepsilon$ & $199,3 \mu \varepsilon$ & $159,4 \mu \varepsilon$ \\
\hline 60 N.m & $257 \mu \varepsilon$ & $298,9 \mu \varepsilon$ & $239,1 \mu \varepsilon$ \\
\hline 80 N.m & $331 \mu \varepsilon$ & $398,5 \mu \varepsilon$ & $318,8 \mu \varepsilon$ \\
\hline 100 N.m & $390 \mu \varepsilon$ & $498,1 \mu \varepsilon$ & $398,5 \mu \varepsilon$ \\
\hline 120 N.m & $441 \mu \varepsilon$ & $597,8 \mu \varepsilon$ & $478,2 \mu \varepsilon$ \\
\hline 140 N.m & $486 \mu \varepsilon$ & $697,4 \mu \varepsilon$ & $557,9 \mu \varepsilon$ \\
\hline 160 N.m & $561 \mu \varepsilon$ & $797,0 \mu \varepsilon$ & $637,6 \mu \varepsilon$ \\
\hline 180 N.m & $613 \mu \varepsilon$ & $896,7 \mu \varepsilon$ & $717,3 \mu \varepsilon$ \\
\hline 200 N.m & $669 \mu \varepsilon$ & $996,3 \mu \varepsilon$ & $797,0 \mu \varepsilon$ \\
\hline 225 N.m & $715 \mu \varepsilon$ & $1120,8 \mu \varepsilon$ & $896,7 \mu \varepsilon$ \\
\hline
\end{tabular}

Utilizando os resultados de deformação, aplicou-se a equação (5-2) com as constantes do parafuso. Com isso, pode-se criar a tabela abaixo com os resultados.

Tabela 7.2: Resultados de Força em função do Torque aplicado

\begin{tabular}{|c|c|c|c|}
\hline Torque & $\begin{array}{c}\text { Força } \\
\text { Experimental }\end{array}$ & $\begin{array}{c}\text { Força } \\
\mathbf{R}=\mathbf{5 0} \mathbf{\%}\end{array}$ & $\begin{array}{c}\text { Força } \\
\mathbf{R}=\mathbf{9 9} \%\end{array}$ \\
\hline 20 N.m & $5,02 \mathrm{kN}$ & $5,00 \mathrm{kN}$ & $3,30 \mathrm{kN}$ \\
\hline 40 N.m & $8,48 \mathrm{kN}$ & $10,00 \mathrm{kN}$ & $6,60 \mathrm{kN}$ \\
\hline 60 N.m & $12,90 \mathrm{kN}$ & $15,00 \mathrm{kN}$ & $9,90 \mathrm{kN}$ \\
\hline 80 N.m & $16,61 \mathrm{kN}$ & $20,00 \mathrm{kN}$ & $13,20 \mathrm{kN}$ \\
\hline 100 N.m & $19,57 \mathrm{kN}$ & $25,00 \mathrm{kN}$ & $16,50 \mathrm{kN}$ \\
\hline 120 N.m & $22,13 \mathrm{kN}$ & $30,00 \mathrm{kN}$ & $19,80 \mathrm{kN}$ \\
\hline 140 N.m & $24,39 \mathrm{kN}$ & $35,00 \mathrm{kN}$ & $23,10 \mathrm{kN}$ \\
\hline $160 \mathrm{~N} \cdot \mathrm{m}$ & $28,15 \mathrm{kN}$ & $40,00 \mathrm{kN}$ & $26,40 \mathrm{kN}$ \\
\hline $180 \mathrm{~N} \cdot \mathrm{m}$ & $30,76 \mathrm{kN}$ & $45,00 \mathrm{kN}$ & $29,70 \mathrm{kN}$ \\
\hline 200 N.m & $33,57 \mathrm{kN}$ & $50,00 \mathrm{kN}$ & $33,00 \mathrm{kN}$ \\
\hline 225 N.m & $35,88 \mathrm{kN}$ & $56,25 \mathrm{kN}$ & $37,13 \mathrm{kN}$ \\
\hline
\end{tabular}




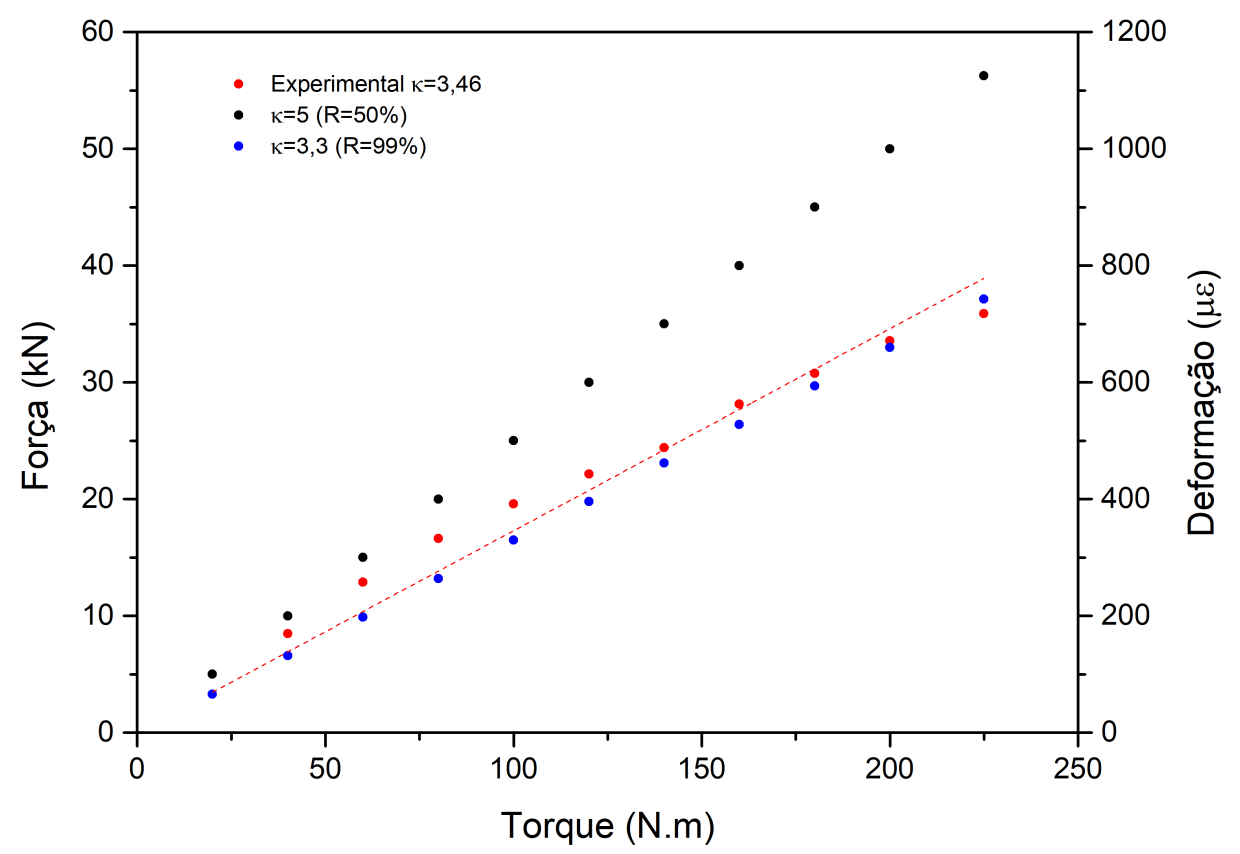

Figura 7.2: Gráfico do resultado de Força vs Torque

Com os resultados de força acima, pode-se determinar a inclinação do ajuste linear dos pontos experimentais. Com esse valor, definiu-se o fator $\kappa_{R}=3,46$. isso significa um valor de confiabilidade de aproximadamente $95 \%$.

\section{2}

\section{Teste de Tração}

Para a realização do teste de tração, necessitou-se alugar durante um dia a máquina MTS 311 do Laboratório de Estruturas e Materiais, sediado na PUCRio. Antes de instalar o corpo de prova na máquina, verificou-se qual a melhor garra, além de qual a melhor posição para encaixar. Os testes foram conduzidos com as garras prendendo na cabeça do parafuso e na porca localizada na outra extremidade. Apesar de ser contraintuitivo, o efeito gerado na junta é o mesmo. Se por um lado os testes convencionais realizam esforços na arruela localizada próxima da cabeça, os esforços acabam sendo transmitidos para o parafuso integralmente. A diferença desse tipo de teste é a praticidade de poder prender diretamente o corpo de prova, sem necessidade de criar acoplamentos ou garras especiais.

O teste de tração consistiu em dois ciclos de subida e descida de cargas. O ciclo verificado foi $\{1 \rightarrow 10 \rightarrow 20 \rightarrow 25 \rightarrow 30 \rightarrow 25 \rightarrow 20 \rightarrow 10 \rightarrow 1\} \mathrm{kN}$. Em paralelo, o fio do terminal de extensômetros foi conectado à caixa medidora de 


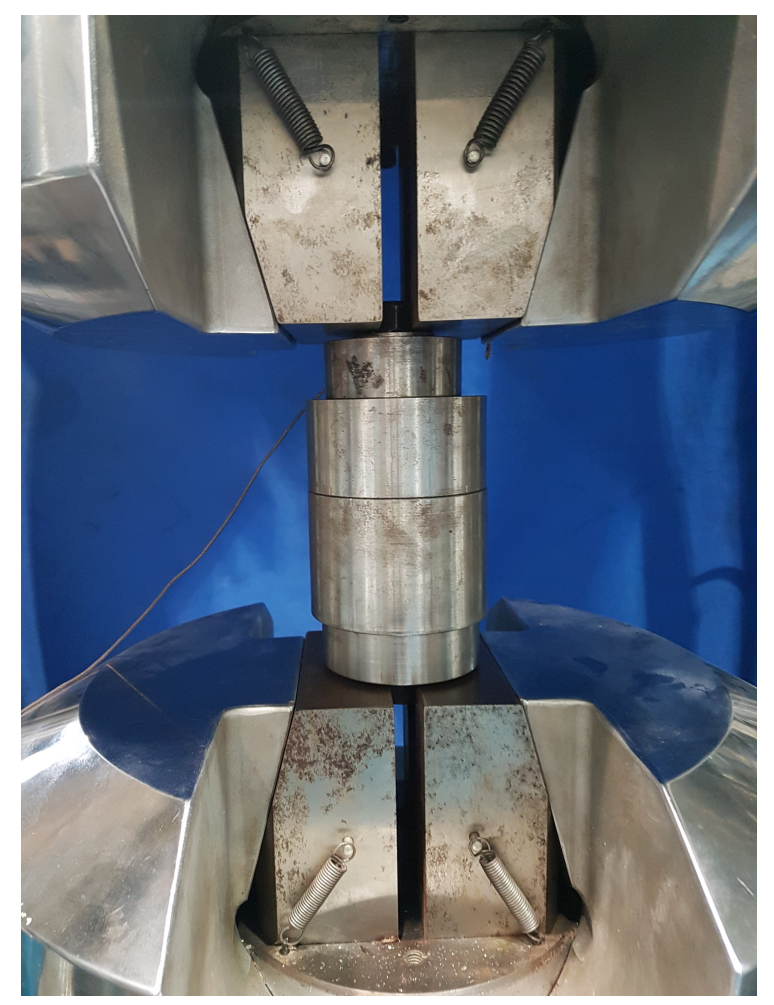

Figura 7.3: Corpo de prova posicionado na máquina de tração

deformação. A compilação dos dados dos dois ciclos realizados encontra-se na figura 7.4. A pré-carga aplicada foi de $28 \mathrm{kN}$.

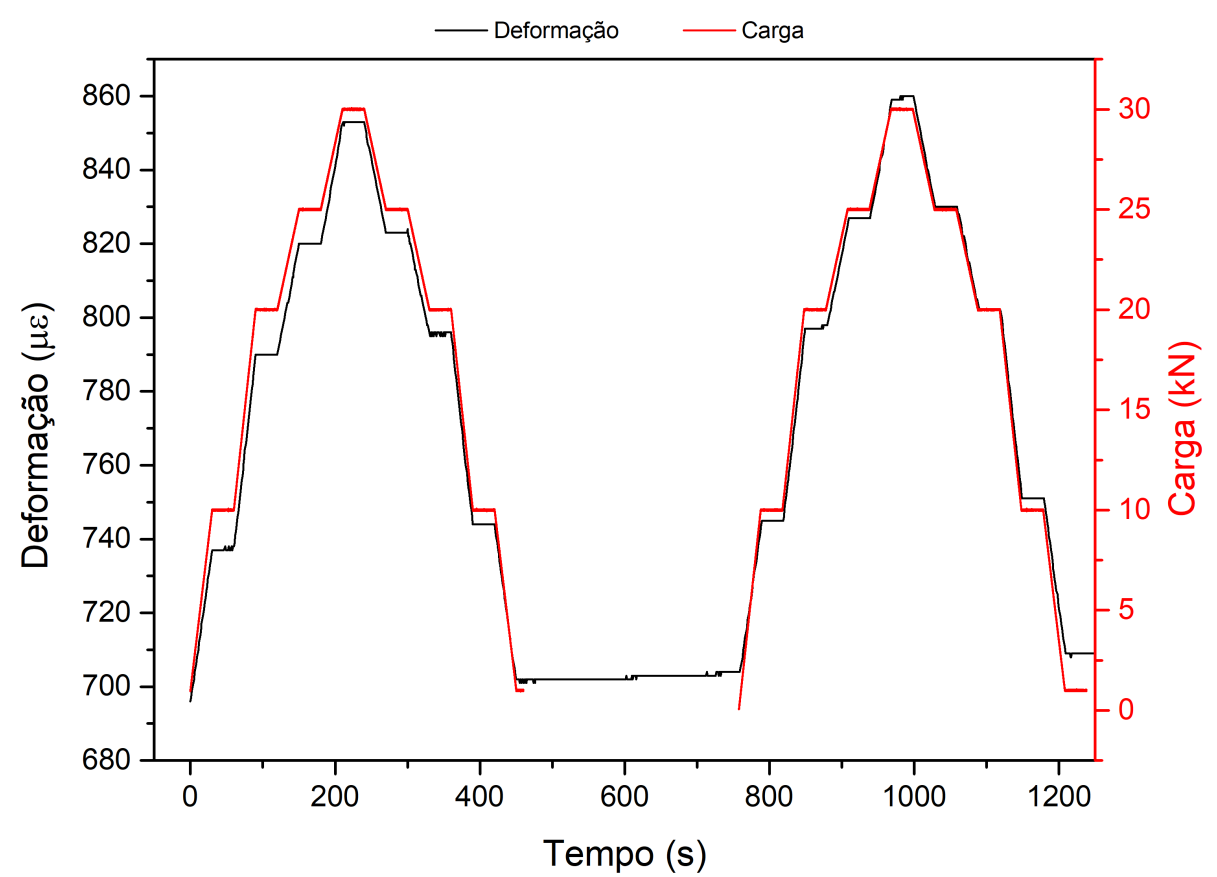

Figura 7.4: Gráfico do resultado do teste de tração 
Com os resultados do teste apresentado acima, foi realizado o processo apresentado na equação (5-6). Os resultados são mostrados na tabela 7.3.

Tabela 7.3: Resultados de Deformação em função do carregamento

\begin{tabular}{|c|c|c|c|}
\hline Carregamento & Deformação Teórica & Deformação Lida & Erro \\
\hline $1 \mathrm{kN}$ & $560 \mu \varepsilon$ & $696 \mu \varepsilon$ & $24 \%$ \\
\hline $10 \mathrm{kN}$ & $578 \mu \varepsilon$ & $737 \mu \varepsilon$ & $27 \%$ \\
\hline $20 \mathrm{kN}$ & $599 \mu \varepsilon$ & $790 \mu \varepsilon$ & $32 \%$ \\
\hline $25 \mathrm{kN}$ & $610 \mu \varepsilon$ & $820 \mu \varepsilon$ & $35 \%$ \\
\hline $30 \mathrm{kN}$ & $620 \mu \varepsilon$ & $853 \mu \varepsilon$ & $38 \%$ \\
\hline
\end{tabular}

Os resultados não podem ser considerados satisfatórios, uma vez que a deformação lida está na case de $30 \%$ diferente da esperada. Isso significa que a aproximação proposta como suposição não é válida para essas condições de contorno.

\section{3}

\section{Teste de Fadiga}

Os testes de cargas cíclicas aconteceram junto ao teste de tração. Foram variadas duas condições máximas de 25 e $30 \mathrm{kN}$, sendo ambos com 500 ciclos. A pré carga foi a mesma do teste anterior de $28 \mathrm{kN}$.

Para definir tais resultados, utilizou-se de base os seguintes valores [5] para os fatores influentes na vida à fadiga.

Tabela 7.4: Fatores utilizados no dimensionamento

\begin{tabular}{|c|c|c|}
\hline Fator & Resultado & Justificativa \\
\hline$k_{a}$ & $4,45 \cdot\left(\sigma_{a}\right)^{-0,265}$ & Parafuso foi Usinado \\
\hline$k_{b}$ & 0,9 & Juvinall sugere tal valor quando $8<d<50$ \\
\hline$k_{c}$ & 1 & Cargas de flexão e torção alternadas \\
\hline$k_{d}$ & 1 & Temperatura não influente \\
\hline$k_{e}$ & 1 & Confiabilidade baixa \\
\hline
\end{tabular}

As tabelas 7.5 e 7.6 apresentam os resultados lidos pela máquina e obtidos pelas contas com base no capítulo 5 . As figuras 7.5 e 7.6, por sua vez, mostram os resultados com os picos de deformação sentida pelo parafuso, além das amplitudes de carga. 
Tabela 7.5: Resultados de Deformação em função do carregamento de máximo $25 \mathrm{kN}$

\begin{tabular}{|c|c|}
\hline Carga Máxima & $25 \mathrm{kN}$ \\
\hline Carga Mínima & $1 \mathrm{kN}$ \\
\hline$\sigma_{a}$ & $46,9 \mathrm{MPa}$ \\
\hline$\sigma_{m}$ & $51,0 \mathrm{MPa}$ \\
\hline$S_{e}$ & $49,0 \mathrm{MPa}$ \\
\hline$S_{e}{ }^{\prime}$ & $3,13 \mathrm{GPa}$ \\
\hline
\end{tabular}

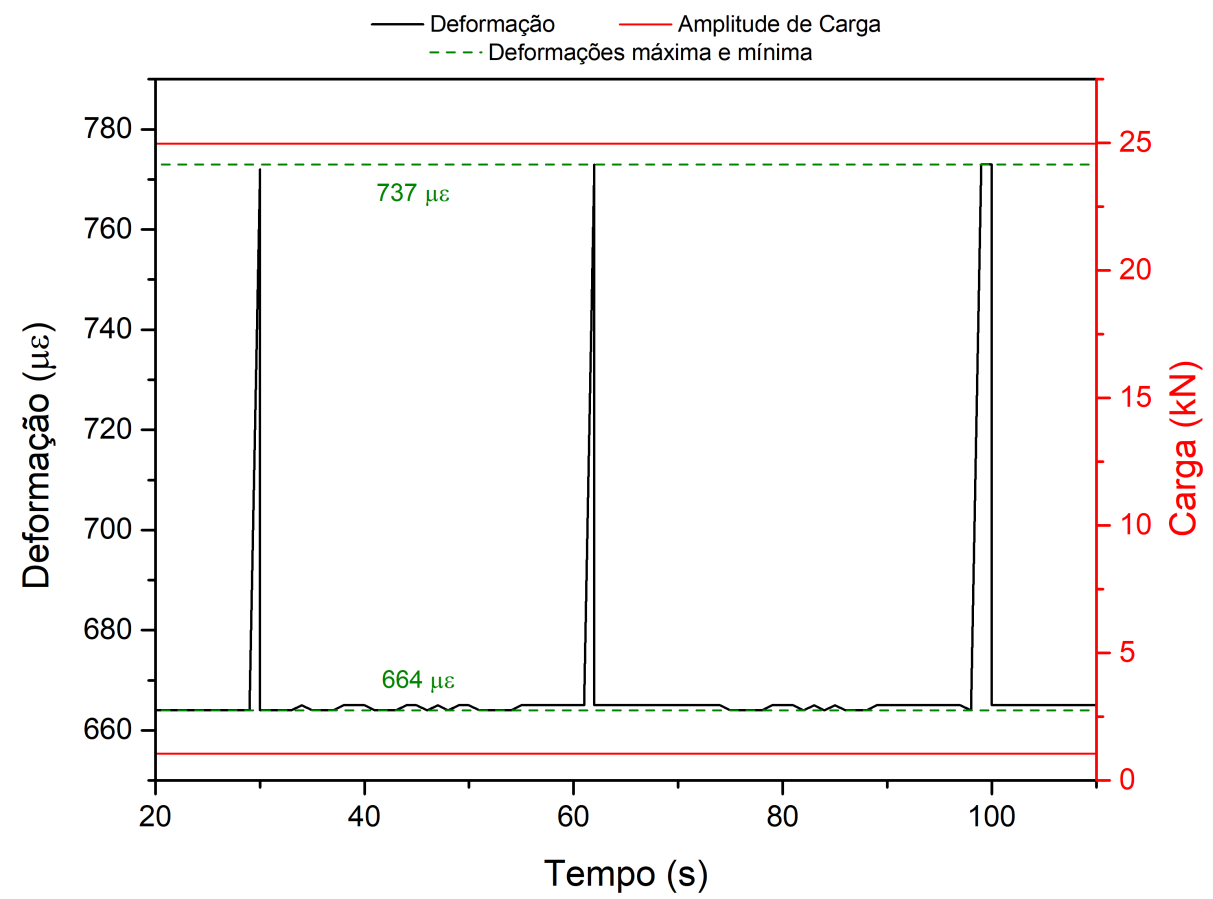

Figura 7.5: Gráfico do resultado do teste cíclico até $25 \mathrm{kN}$ 
Tabela 7.6: Resultados de Deformação em função do carregamento de máximo $30 \mathrm{kN}$

\begin{tabular}{|c|c|}
\hline Carga Máxima & $30 \mathrm{kN}$ \\
\hline Carga Mínima & $1 \mathrm{kN}$ \\
\hline$\sigma_{a}$ & $59,2 \mathrm{MPa}$ \\
\hline$\sigma_{m}$ & $63,3 \mathrm{MPa}$ \\
\hline$S_{e}$ & $62,4 \mathrm{MPa}$ \\
\hline$S_{e}{ }^{\prime}$ & $3,99 \mathrm{GPa}$ \\
\hline
\end{tabular}

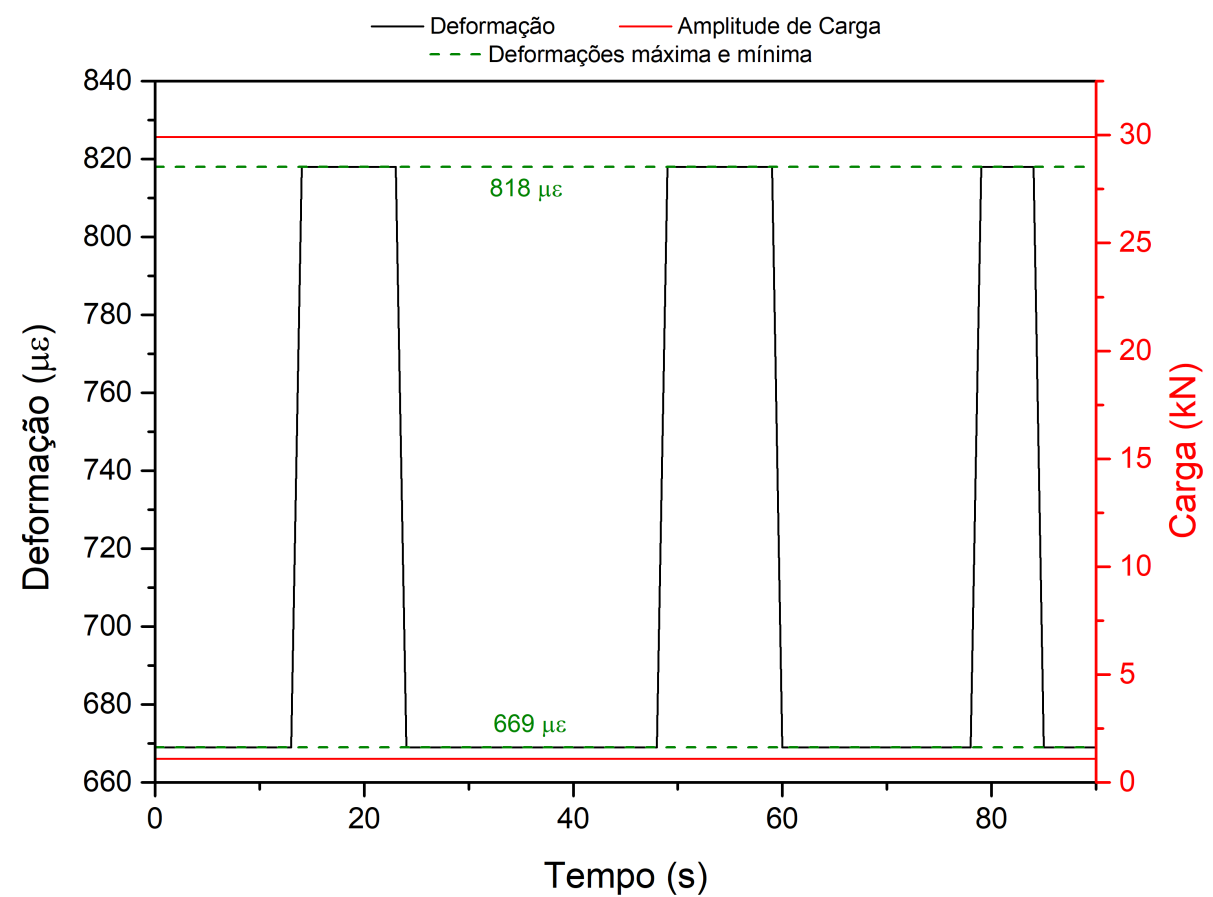

Figura 7.6: Gráfico do resultado do teste cíclico $30 \mathrm{kN}$

Ambos os valores ficaram distantes do valor de $120 \mathrm{MPa}$ sugeridos por Shigley. A maior possibilidade é a determinação da força de aperto inicial (pré-carga) que pode ter sido insuficiente para auxiliar as medições. 


\section{8 \\ Conclusões}

Todo o presente trabalho foi estruturado para comprovar técnicas e previsões utilizadas corriqueiramente e com pouca verificação atual. Ao longo do texto, diversos métodos e pressuposições foram expostos de maneira a facilitar e envolver o leitor no universo do dimensionamento de parafusos. Além do conhecimento teórico, foram expostos também conhecimentos experimentais de colagem de extensômetros e programação de testes.

Contudo, os valores checados não correspondem com as suposições feitas ao longo do texto. O fato de isso ter ocorrido é em relação à modelagens conservadoras demais, e por falhas de informações mais precisas, tais como propriedades dos materiais.

Dentre os três testes propostos, o que obteve melhor resultado foi o da relação Torque vs Força. O resultado mostrou-se consistente com os valores sugeridos pela a literatura. O índice de confiabilidade, inclusive, se mostrou alto (95\%) para as características do teste. Isso significa que as medidas acabaram sendo até menos conservadoras do que atualmente é empregado.

Contudo, nos testes de tração e fadiga, os resultados não foram satisfatórios. Em relação ao teste de carga, as leituras mostraram-se mais altas do que deveriam, na casa de 30\% do valor esperado. Apesar de todo teste possuir margem de incertezas, esse valor é muito mais alto do que o esperado. Acredita-se que essas deformações foram lidas de maneira correta, porém com algum deslizamento de garra ao segurar o parafuso durante os carregamentos, por exemplo.

Outro fator não menos importante é a definição da rigidez dos membros. O valor utilizado foi fruto de uma equação apresentada por Juvinall, porém com outras condições de contorno. Percebeu-se que o fato de serem outras condições diferentes das testadas influencia diretamente nos resultados. O método do tronco de cone é mais conservador nesse sentido, sendo então mais recomendado. 


\section{Sugestões para trabalhos futuros}

Apesar de os resultados não estarem compatíveis com as expectativas, todo esse trabalho gerou inúmeras questões e sugestões para trabalhos futuros.

A começar pela modelagem, sugere-se fortemente investir na modelagem pelo método do cone de pressão para determinar a rigidez de membros. Essa modelagem não foi aprofundada por falta de informações específicas sobre o acoplamento entre as bolachas de aço.

Uma ideia interessante, em paralelo à nova modelagem, é o uso de apenas dois membros e de tamanhos similares, lembrando também das dimensões de requisitos para testes. Utilizar o conjunto como esse citado facilita o desenvolvimento e torna mais simples sua análise, não obstante de uma validação.

Uso de verniz isolante para motores elétricos, tais como Isolasil 7200. Tais vernizes protegem de maneira mais eficiente os contatos do extensômetro e diminui possibilidades de interferências, contudo exigem secagem em estufa.

Recomenda-se o uso de uma máquina de tração com frequências menores à $1 \mathrm{~Hz}$. Isso favorece a visualização de resultados dinâmicos quando o interesse é visualizar os picos e vales. Importante também ter uma melhor central para aquisição de dados. O P3 da Vishay é muito bom, seguro e confiável, porém não gera dados com a frequência necessária para melhores resultados.

Um fato interessante seria também analisar o efeito previsível de materiais mais macios ou rígidos entre juntas aparafusadas e como isso afeta a vida à fadiga do parafuso. Essa sugestão pode ser empregada como continuação deste trabalho. 


\section{Referências Bibliográficas}

[1] Site metalica - parafusos: definição e tipos, http://wwwo.metalica.com.br/artigos-tecnicos/parafusos.

[2] Richard G. Budynas and J. Keith Nisbett. Shigley's Mechanical Engineering Design. McGraw-Hill Higher Education, 10th edition, 2014.

[3] Site enerpac - teoria de aparafusamento, https://www.enerpac.com/pt$\mathrm{br} /$ treinamento/e/bolting-theory.

[4] J.G. Williams, R.E. Anley, D.H. Nash, and T.G.F. Gray. Analysis of externally loaded bolted joints: Analytical, computational and experimental study. International Journal of Pressure Vessels and Piping, 86(7):420 427, 2009.

[5] MA Meggiolaro and JTP De Castro. Fadiga - Tecnicas E Praticas de Dimensionamento Estrutural Sob Cargas Reais de Servico, volume I Iniciacao de Trincas. Createspace IPP, 2009.

[6] R.C. Juvinall and K.M. Marshek. Fundamentals of Machine Component Design. Wiley, 5th edition, 2011.

[7] J.W. Dally and W.F. Riley. Experimental Stress Analysis. McGraw-Hill series in mechanical engineering. McGraw-Hill, 3rd edition, 1991.

[8] E.L. Grimsmo, A. Aalberg, M. Langseth, and A.H. Clausen. Failure modes of bolt and nut assemblies under tensile loading. Journal of Constructional Steel Research, 126:15 - 25, 2016.

[9] Henrik Wentzel and Xiyue Huang. Experimental characterization of the bending fatigue strength of threaded fasteners. International Journal of Fatigue, 72:102 - 108, 2015.

[10] J. Bickford. Handbook of Bolts and Bolted Joints. CRC Press, 1998.

[11] R.L. Norton. Machine Design: An Integrated Approach. Pearson, 2011.

[12] Iso 898-1. mechanical properties of fasteners made of carbon steel and alloy steel - part 1: Bolts, screws and studs with specified property classes - coarse thread and fine pitch thread, 2013. 
[13] Sandro Griza, Marcio Erick Gomes da Silva, Silvando Vieira dos Santos, Everton Pizzio, and Telmo Roberto Strohaecker. The effect of bolt length in the fatigue strength of $\mathrm{m} 24 \times 3$ bolt studs. Engineering Failure Analysis, $34: 397-406,2013$.

[14] J.W Hobbs, R.L Burguete, P.F Heyes, and E.A Patterson. The effect of eccentric loading on the fatigue performance of high-tensile bolts. International Journal of Fatigue, 22(6):531 - 538, 2000.

[15] I. Korin and J. Perez Ipiña. Experimental evaluation of fatigue life and fatigue crack growth in a tension bolt-nut threaded connection. International Journal of Fatigue, 33(2):166 - 175, 2011.

[16] Jaime Tupiassú. Notas de aula - elementos de máquina - puc-rio, 2017.

[17] LARYCE SOUZA DA SILVA. AvaliaÇÃo comparativa do comportamento mecÂnico e tribolÓgico de dois parafusos da classe 10.9 astm. Master's thesis, UENF, 2017.

[18] Carlos Felipe Espiúca Monteiro. Sistemas especialistas - projeto de parafusos de uniÃo. Master's thesis, UFRJ, 2014.

[19] RAPHAEL CALAZANS CARDOSO. AvaliaÇÃo da rigidez axial de juntas parafusadas. Master's thesis, UFS, 2018.

[20] Éverton Pizzio. Avaliação da vida em fadiga de uniões parafusadas. Master's thesis, UFRGS, 2005. 